Review Article

\title{
A review on the origin of nanofibers/nanorods structures and applications
}

\author{
K. Chandra Babu Naidu $\mathbb{D}^{1} \cdot$ N. Suresh $\mathrm{Kumar}^{2} \cdot$ Prasun Banerjee $^{1} \cdot$ B. Venkata Shiva Reddy ${ }^{1,3}$
}

Received: 28 October 2020 / Accepted: 30 May 2021 / Published online: 12 June 2021

(c) The Author(s) 2021

\begin{abstract}
In this review work, we highlight the origin of morphological structures such as nanofibers/nanorods in case of various materials in nano as well as bulk form. In addition, a discussion on different cations of different ionic radii and other intrinsic factors is provided. The materials (ceramic titanates, ferrites, hexaferrites, oxides, organic/inorganic composites, etc.,) exhibiting the nanofibers/nanorods like morphological structures are tabulated. Furthermore, the significance of nanofibers/ nanorods obtained from distinct materials is elucidated in multiple scientific and technological fields. At the end, the device applications of these morphological species are also described in the current technology.
\end{abstract}

\section{Graphical Abstract}

The nucleation and growth mechanism of $\alpha-\mathrm{MnO}_{2}$ nanorods using natural extracts from Malus domestica and Vitis vinifera [3].

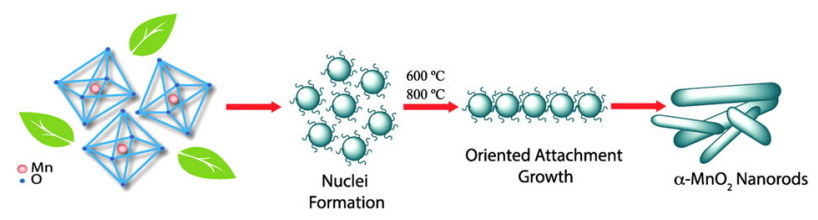

\section{Introduction}

It is a known fact that nanotechnology is an innovative research area, and it develops various materials and devices on nanoscale (diameter of $10^{-9} \mathrm{~m}$ ). To identify the nano ordered species within a material, the surface morphology of the same is a well-suited study. In addition, the morphology of different materials can be considered as an important parameter for

K. Chandra Babu Naidu

chandrababu954@gmail.com

1 Department of Physics, GITAM Deemed to be University, Bangalore 562163 Karnataka, India

2 Department of Physics, JNTUA, Anantapuramu 515002 Andhra Pradesh, India

3 Department of Physics, The National College, Bagepalli 561207 Karnataka, India achieving advanced properties. In view of this, ample of nanostructures such as nanospheres, nanoplates, nanorods, nanofibers, nanowires, nanoflowers, nanoleaves, nanotubes, nanocages, nanofilms, nanoparticles, nanosheets, nanochains, nanofoam, nanoholes, nanomesh, nanopillar, nanorings, nanoribbons, nanoshells, nanocubes, quantum wells, quantum dots etc., are evolved because of synthesizing nanomaterials via different synthesis techniques [1]. All these structures are very interesting and similarly, they provide peculiar properties along with scientific and technological applications. Moreover, the rapid development of science and technology is established owing to the formation of the above-said nanostructures.

Among all the nanostructures, the nanofibers/nanorods are different and the easiest structures to prepare. Many scientists put their efforts to develop nanofibers/nanorods like morphological species using electrospinning and hydrothermal techniques [2]. Out of these two methods, the electrospinning method is an expensive, time consuming, and laborious process [2]. On the other hand, the hydrothermal method offers several advantages like in expensive, less time consuming, easy preparation, and good homogeneity [2]. 


\subsection{Origin of nanofibers/nanorods like morphology}

The nanofibers look to be flexible in nature while the nanorods will have rigidity in nature. Normally, the nanofibers/nanorods can be formed by the generation and growth of the nuclei of the material in vertical/horizontal direction. Besides, the heterogeneous nucleation will be reinforced at the solid interface owing to the deposition of catalytic clusters. During this kind of mechanism, the formed uniform nanopores can act as the templates for the nanofibers. The filled nanopores produce nanorods. This indicates that the nanorods will have apparent high dense structure rather than the nanofibers. The schematic representation for the formation of $\alpha-\mathrm{MnO}_{2}$ nanorods via the nucleation process is shown in Fig. 1 [3]. After forming the nuclei, the nuclear clusters are being heated at 600 and $800^{\circ} \mathrm{C}$ temperatures. Consequently, some of the nuclei are oriented in direction while few are oriented in other directions. This leads to the formation of vertical/horizontal $\alpha-\mathrm{MnO}_{2}$ nanorods (NRs). Similarly, the nanofibers will be formed containing the flexible (less rigidity) structure. It is a known fact that the nanorods show the different facets in the compound. This kind of behavior is indeed attributed due to the combination of ligands that act as the shape control agents offering different strengths to the nanorods. Therefore, various faces will be acquired by the nanorods with different growth and elongation rates. Herein, the ligand is a molecule/ion, and it can bind the metal atoms located at the central position in order to develop the complex system. It comprises Fe as the

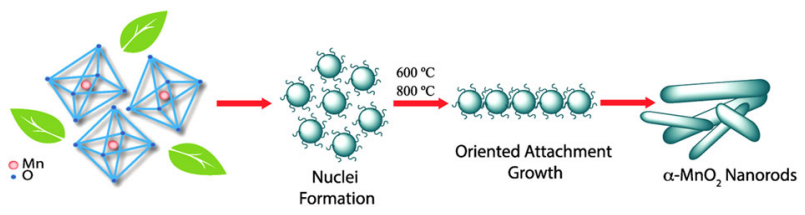

Fig. 1 Schematic representation of the proposed nucleation and growth mechanism of $\alpha-\mathrm{MnO}_{2}$ nanorods using natural extracts from Malus domestica and Vitis vinifera [3] central metal ion position, $\mathrm{K}_{4}$ as the counter ion position, $(\mathrm{CN})_{6}$ as the ligand, and $\left[\mathrm{Fe}(\mathrm{CN})_{6}\right]$ as the coordination position. Moreover, these ligands are normally considered as the electron donors attracted $\mathrm{O}$ the $\mathrm{Fe}$ (metal atom) at the center of the complex system.

\subsection{Electrospinning technique}

Electrospinning is a synthesis technique of nanofibers with nano/micrometer size, wherein the electrostatic forces will be produced from the polymer-based material solution. For the preparation of nanofibers, the conventional spinning process is used as shown in Fig. 2 [4]. In this process, the DC input voltage is required to develop the electrospinning. Herein, the strong electrical repulsive forces dominate the weaker surface tension forces of the polymer material solution. Within the conventional electrospinning process, the vertical and horizontal techniques generate the nanofibers. These are conducted at normal atmospheric conditions. This system includes the high voltage power supply, spinneret, and collector. The high voltage is used to inject charge into the polymer material solution. In the meantime, the polymer solution is introduced into the capillary tube. In addition, it is to be taken care that the poisonous gasses will be released during the synthesis process. For this purpose, the ventilation chamber is provided to the whole system. At this moment, the electric field is switched on and then, the electrostatic repulsive forces will overcome the weak surface tension forces. As a result, the solution is accelerated towards the collector. On reaching the collector plate, the solvent will be evaporated leaving the polymer on the plate. Thus, the nanofibers will be formed on the plate which can be identified by the high resolved and sophisticated equipment such as FESEM and HRTEM. The PAA/PVA electro-spun nanofibers are shown in Fig. 3 [5]. It is understood that the nanofibers present in SEM picture show an apparent flexibility in nature. On the other hand, the TEM picture of as prepared Au NRs reveals the significant rigidity in nature owing to the less pore portion of the structure.
Fig. 2 Schematic representation of nanofiber preparation with a vertical set up and $\mathbf{b}$ horizontal set up [4] a)

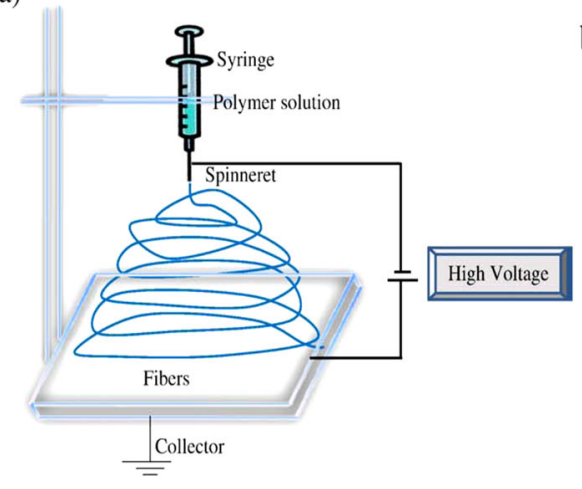

b)

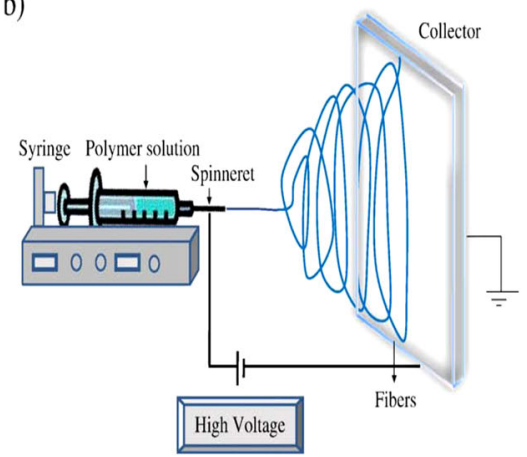




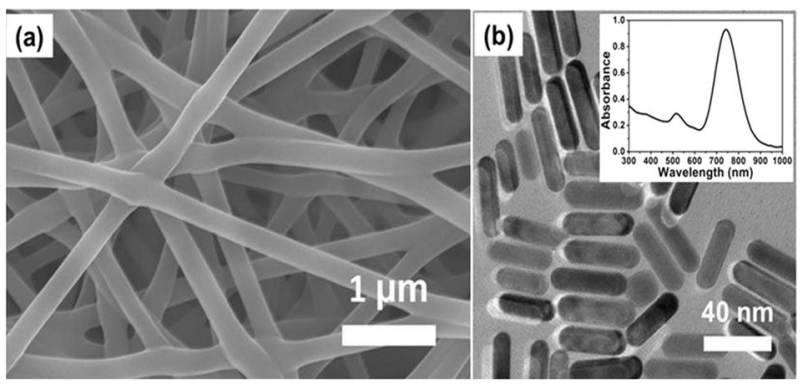

Fig. 3 a SEM image of the PAA/PVA electro spun nanofibers; b TEM image and UV-vis spectrum of the as-prepared Au NRs [5]

\subsection{Hydrothermal technique}

The hydrothermal method is also preferable to prepare the nanofibers/nanorods. For this, several scientists considered the nitrate materials as the precursors. For instance, the BaSrLa$\mathrm{Fe}_{12} \mathrm{O}_{19}$ nanorods are prepared via the hydrothermal process as. Herein, the nitrate precursors are selected as the starting materials. After dissolving the precursors in the distilled water, the $\mathrm{NaOH}$ solution is added drop by drop to maintain the $\mathrm{pH}$ value. The stirred solution is transferred to $300 \mathrm{ml}$ autoclave and kept in an oven to perform the hydrothermal reaction at $150^{\circ} \mathrm{C}$ for $8 \mathrm{~h}$. In this method, the reaction temperature can be varied between 120 and $200^{\circ} \mathrm{C}$ based on the kind of material compound. During the reaction, owing to the pressure and temperature developed in the autoclave, the nucleation process will be taken place. This will be occurred due to the presence of high and small ionic radii elements in the compound. In addition, different valence position of cations is also responsible for this kind of behavior. Once, the reaction is over, the sample is removed from the autoclave and then, it is washed multiple numbers times to keep the $\mathrm{pH}$ value neutral. Then, the powder sample is heated at $60^{\circ} \mathrm{C}$ to remove the moisture content. The FESEM picture of $\mathrm{BaSrLaFe}_{12} \mathrm{O}_{19}$ reveals the pure nanorods (NRs) as shown in Fig. 4 [2]. Similarly, the SEM picture of $\mathrm{CoSe}_{2} / \mathrm{Mo}_{2} \mathrm{C} / \mathrm{C}$ nanofibers prepared via the hydrothermal method is provided in Fig. 5 [6]. This picture evidence the flexible structure, wherein the pore portions are filled incompletely. The evolution of rectangular nanorods is originated from the substitution of La and Ba-elements of high ionic radii and different valence positions. Several reasons are observed for the formation of $\mathrm{BaSrLaFe}_{12} \mathrm{O}_{19}$ nanorods like the crystal structure, bonding preferences, kind of ions, pressure, temperature, surfactant, and $\mathrm{pH}$ as reported by Sunaina et al. [7]. In the literature also, Kumar et al. [8, 9], prepared the PLCT $\quad\left(\mathrm{Pb}_{0.8-\mathrm{y}} \mathrm{La}_{\mathrm{y}} \mathrm{Co}_{0.2} \mathrm{TiO}_{3} \quad(y=0.2-0.8)\right), \quad$ and PCLT $\left(\mathrm{Pb}_{0.8} \mathrm{Co}_{0.2-\mathrm{z}} \mathrm{La}_{\mathrm{z}} \mathrm{TiO}_{3}(z=0.05-0.2)\right)$ samples via the microwave processed sol-gel method. The obtained results exhibited the nanofibers-like structures in the morphology. Similarly, the BCLF $\left(\mathrm{Ba}_{0.2} \mathrm{Cu}_{0.8-\mathrm{x}} \mathrm{La}_{\mathrm{x}} \mathrm{Fe}_{2} \mathrm{O}_{4} \quad(x=0.2-0.6)\right)$, and BCF $\left(\mathrm{Ba}_{x} \mathrm{Cu}_{1-x} \mathrm{Fe}_{2} \mathrm{O}_{4} \quad(x=0.2-0.8)\right)$ samples prepared via the hydrothermal method reveal the nanorod/nanofibers in the

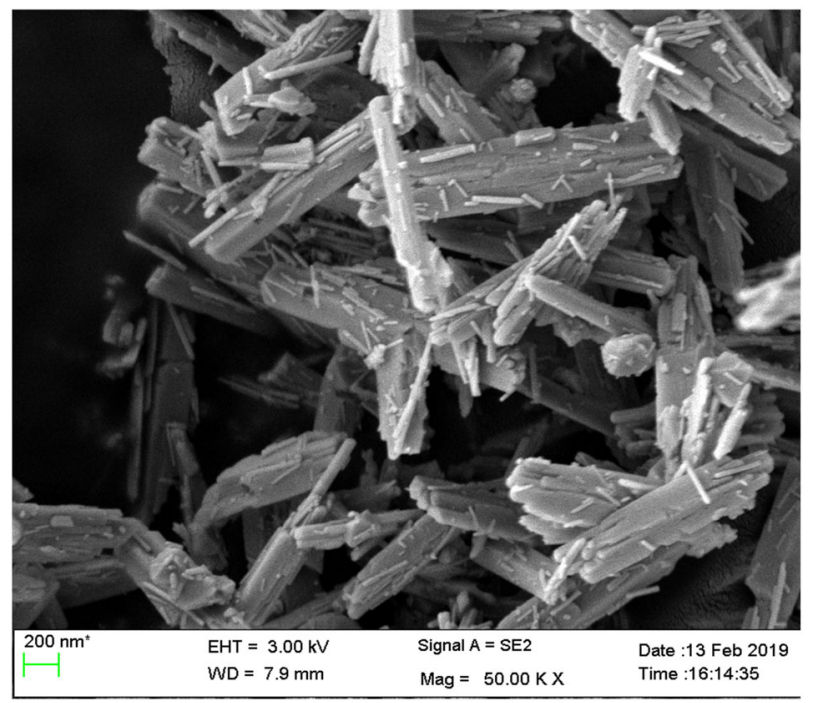

Fig. 4 FESEM pictures of $\mathrm{BaSrLaFe}_{12} \mathrm{O}_{19}$ nanorods prepared via hydrothermal method [2]

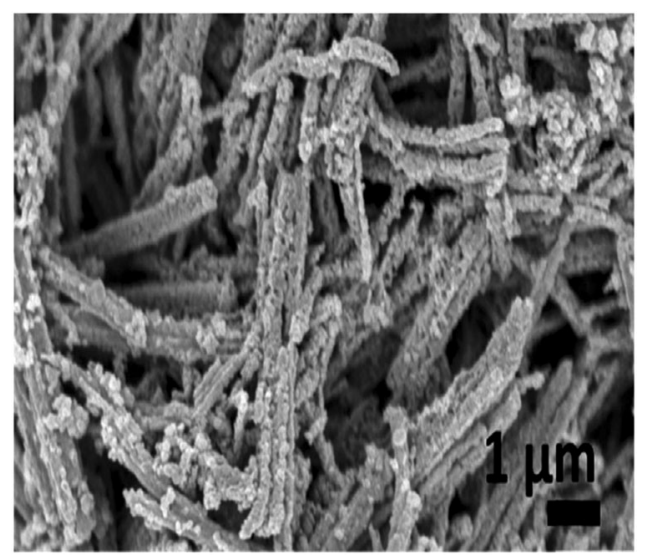

Fig. $5 \mathrm{SEM}$ picture of $\mathrm{CoSe}_{2} / \mathrm{Mo}_{2} \mathrm{C} / \mathrm{C}$ nanofibers prepared via hydrothermal method [6]

morphology as reported by Naresh et al. [10, 11]. BVS Reddy et al. [12,13], synthesized the ALTBT nanocomposites consisting of the nanorods-like structures. Herein, the PLCT, PCLT, BCLF, and ALTBT nanostructures show the complete nanofiber/nanorods at high percentage of $\mathrm{La}^{+3}$ cations, whereas the $\mathrm{BCF}$ samples perform the same nature at high percentage of $\mathrm{Ba}^{+2}$ cations of high ionic radii. The similar observations are noticed by Prakash et al. [14], in case of $\mathrm{BaCuLaTiO}_{3}$ nanorods prepared using the hydrothermal method.

\section{Materials exhibiting the nanofibers/ nanorods like structures and applications}

It is a known fact that the materials are classified into several families based on the adapted structure. In view of 


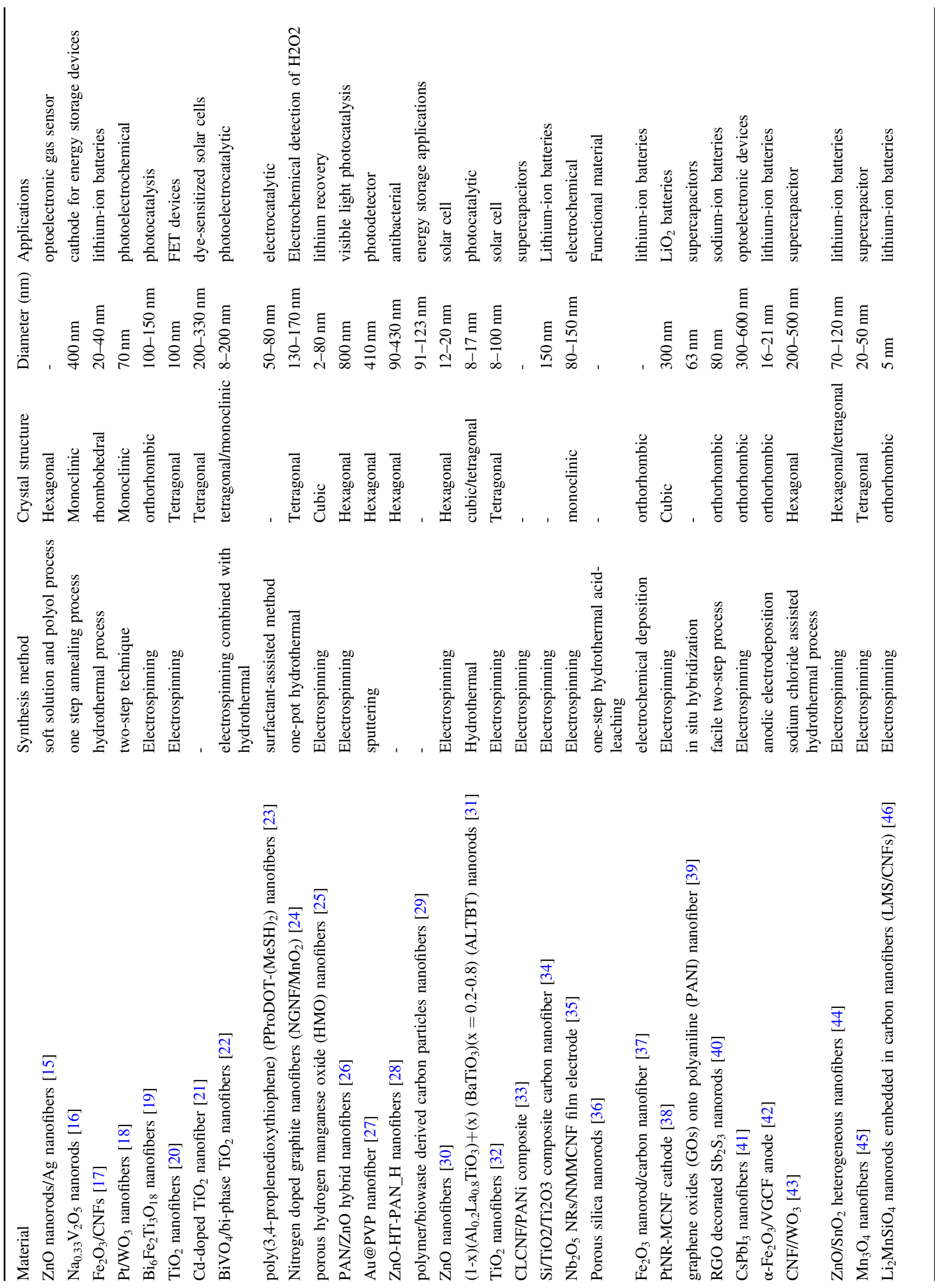




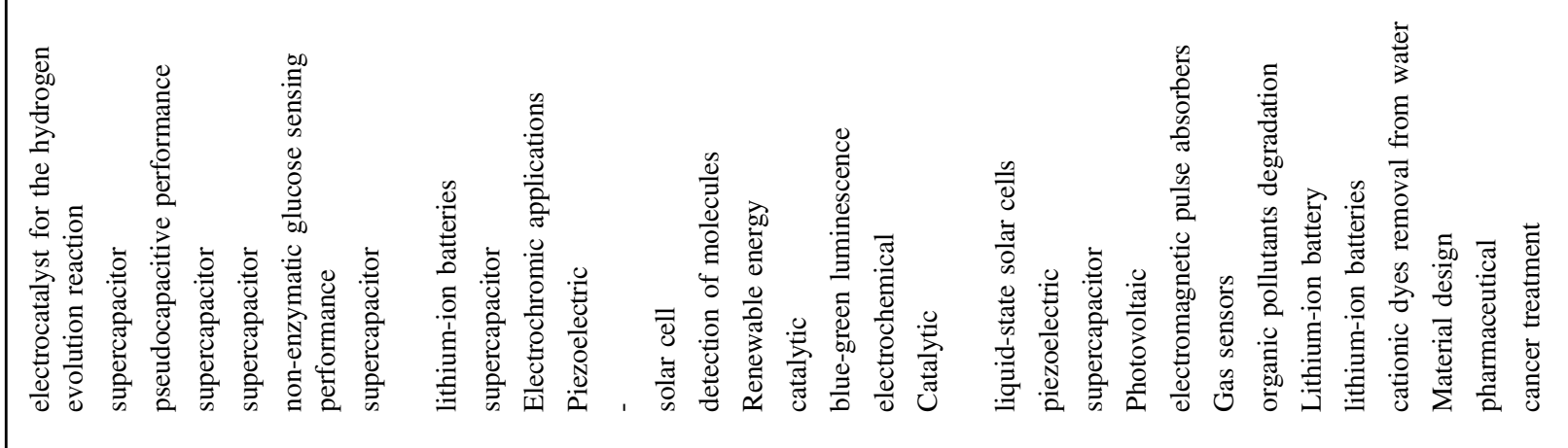

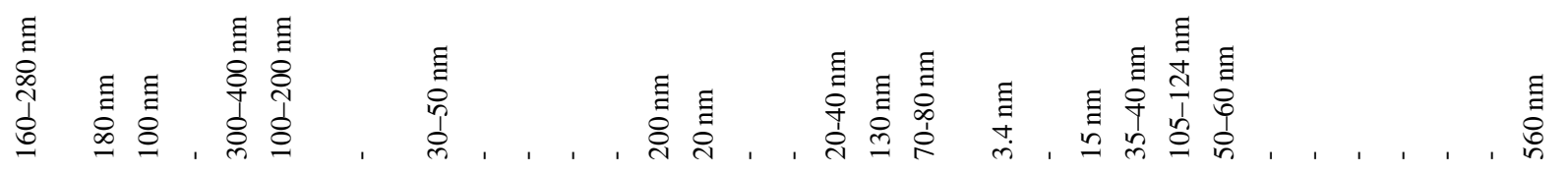

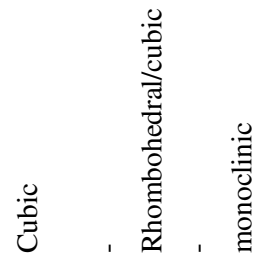

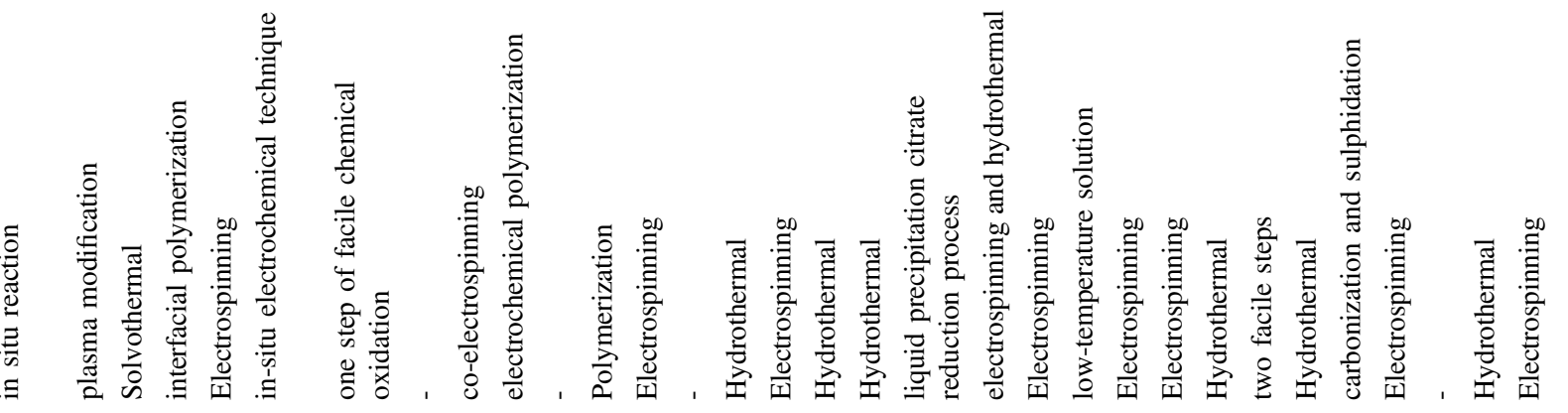

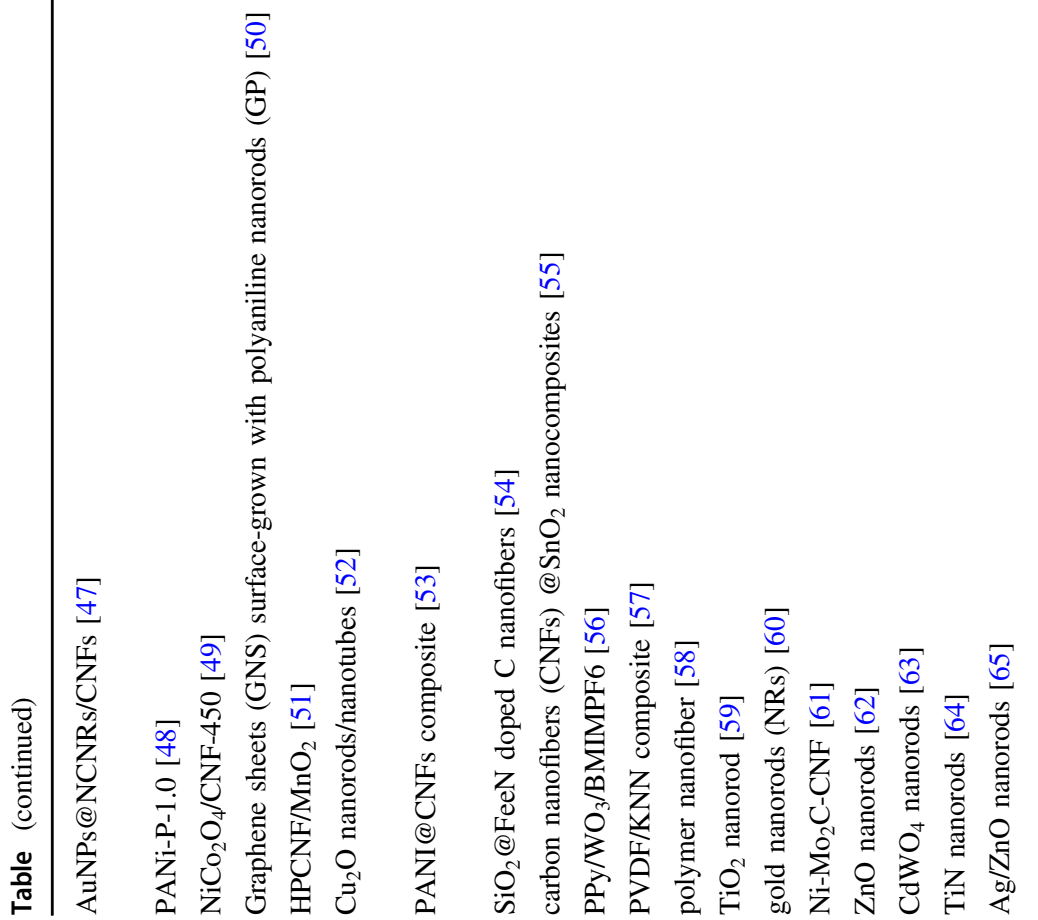

M. ||$M||$ 


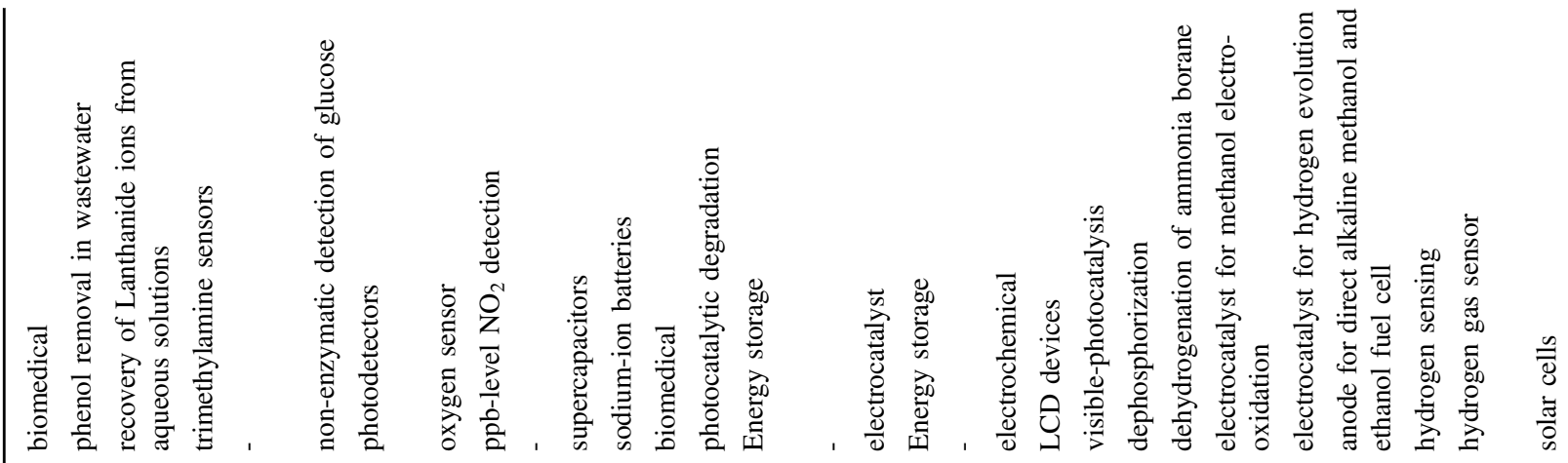

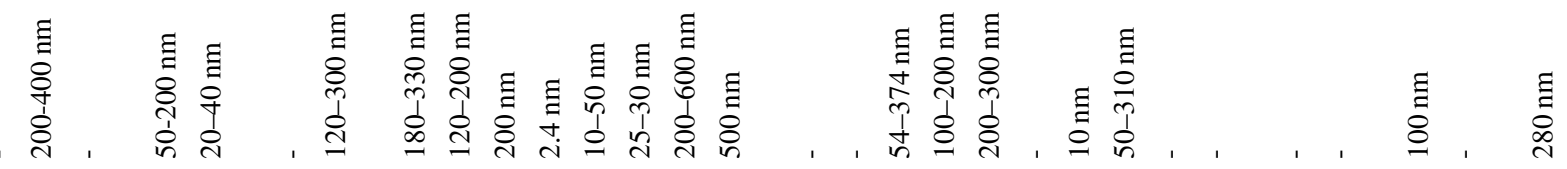

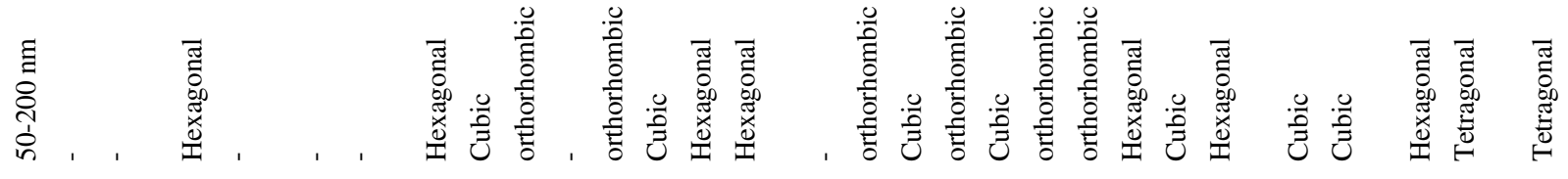

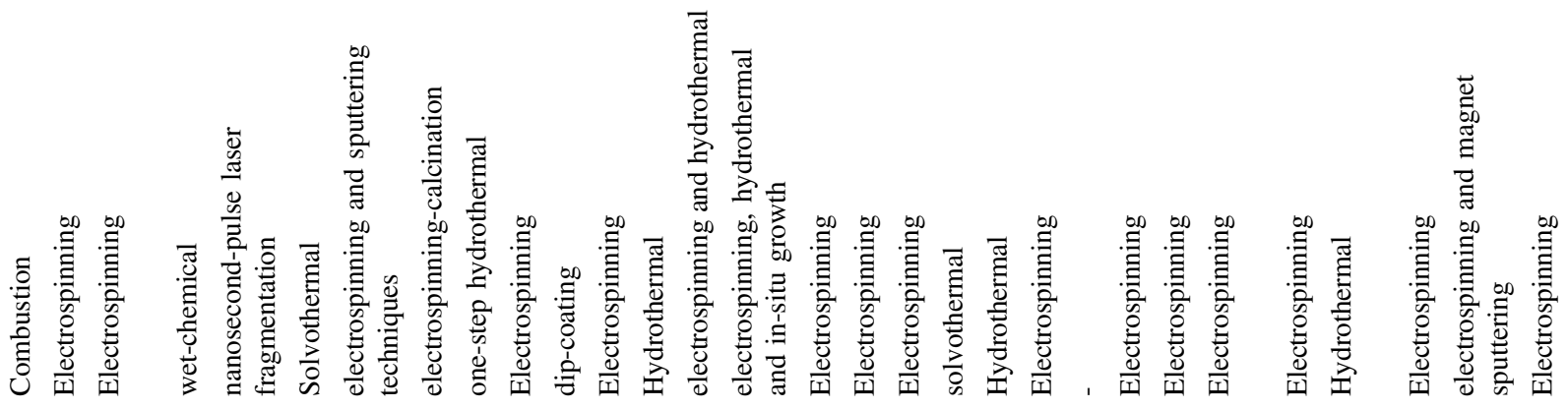

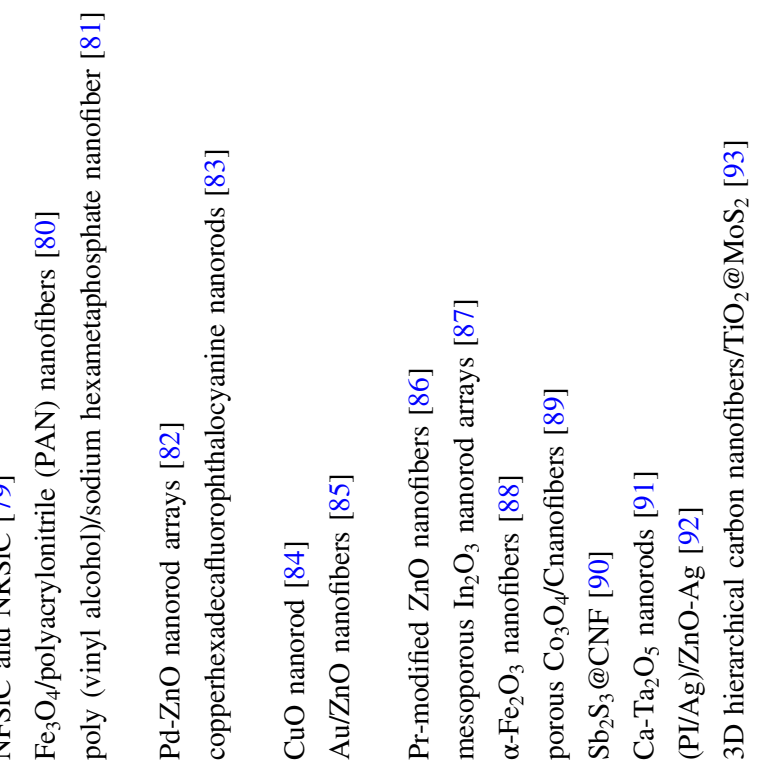

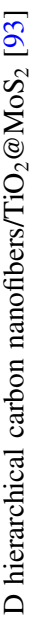

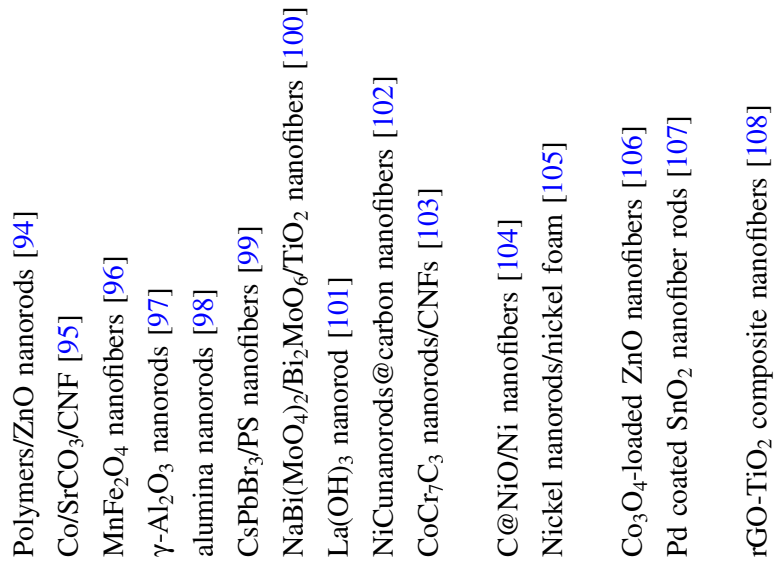




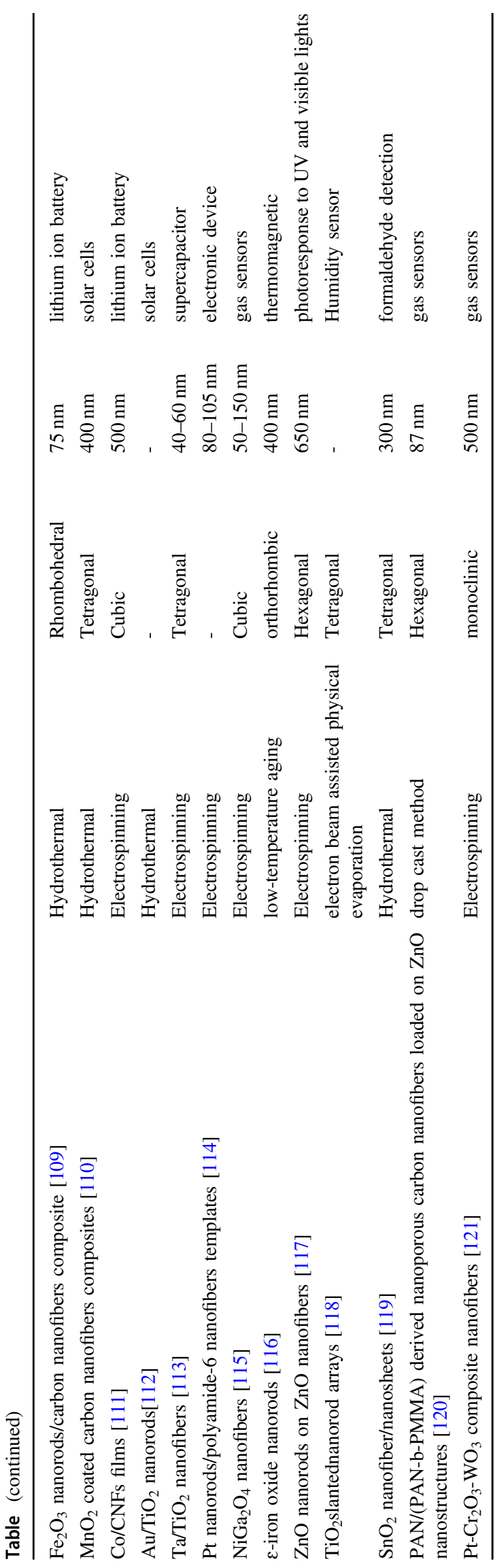

this, the perovskites, spinels, nanocomposites, polymer composites, oxides, etc., are the popular materials achieving the nanofibers/nanorods like structures in the morphology. In Table1, the type of materials, synthesis method, applications etc., are represented. Lingmin et al. [15], prepared the $\mathrm{ZnO}$ nanorods/Ag nanofibers via soft solution and polyol process. The formed resultant structure was noticed to be hexagonal, wherein the optoelectronic gas sensor applications were obtained.

The varieties of nanorods or nanofibers have been prepared for different applications via different techniques. The $\mathrm{ZnO}$ nanorods and $\mathrm{Ag}$ nanofibers with hexagonal structures have been prepared on the chip via soft solution and polyol process. These nanomaterials are used as an optoelectronic gas sensor to identify the gases in surroundings such gas is commonly $\mathrm{NO}_{2}$, ethanol, $\mathrm{CO}$, and $\mathrm{CH}_{4}$ with $\mathrm{UV}$ radiation assistance at the room temperature. The mere zinc oxide $(\mathrm{ZnO})$ is not up to the mark to sense the gas at room temperature as the smaller number of electron carrier's generation on the surface of the $\mathrm{ZnO}$. Therefore, the silver (Ag) nanoparticles have been incorporated into $\mathrm{ZnO}$ structures to defeat the drawbacks so that to exhibit sensor application at the room temperature [15]. The one-dimensional vanadium oxide-based nanomaterials also exhibit gas sensor applications along with spin injection applications or model catalyst. The major advantages of oxides are many synthesis techniques which are sol-gel, hydrothermal, electrospinning, controllable self-assembly process. But the most effective method to prepare vanadium oxide is via annealing process. The high-temperature maintenance during annealing process morphological changes takes place and transition takes place from nanofibers to nanorods. Thus, formed nanorods have tens of microns in length and width around $400 \mathrm{~nm}$ [16]. The recent and major research is emphasized on the lithium-ion batteries in which the electrode materials play an important role in the storage of energy. The electrode materials are $\mathrm{Fe}_{2} \mathrm{O}_{3} / \mathrm{CNFs}$ which are synthesized by hydrothermal process and gives raise to rhombohedral structures with $20-40 \mathrm{~nm}$ of diameter. The iron oxides used in these batteries are nontoxic and eco-friendly in nature. In many research papers reported that the gravimetric and volumetric capacities $1000 \mathrm{mAh} / \mathrm{g}$ and $5300 \mathrm{~mA} \mathrm{~h} \mathrm{ml}{ }^{-1}$, respectively which are higher than the graphite electrodes. Lithium-ion batteries are the rechargeable and highest energy density batteries used in hybrid; plug in hybrid and electronic transport vehicles [17]. The $\mathrm{Pt} / \mathrm{WO}_{3}$ and $\mathrm{BiVO}_{4} /$ bi-phase $\mathrm{TiO}_{2}$ nanofibers exhibit photoelectrochemical and photo-electrocatalytic applications. In the two-step technique $\mathrm{Pt} / \mathrm{WO}_{3}$ nanofibers could be synthesized with a monolithic structure with $70 \mathrm{~nm}$ diameter. The tungsten oxide is an n-type semiconductor with very narrow bandgap about 2.6 to 2.8 range and considered as a good photocatalyst. From the tungsten oxide nanorods, nanofibers and 
nanoplates can be prepared but the nanofibers are the most preferable because of high length to diameter ratio. The $\mathrm{BiVO}_{4} /$ bi-phase $\mathrm{TiO}_{2}$ nanofibers prepared by the electrospinning combined with hydrothermal process gives tetragonal/monoclinic with a range of $8-200 \mathrm{~nm}$ diameters. The $\mathrm{TiO}_{2}$ based materials are eco-friendly and applied to decompose organic contaminants, reduction of carbon dioxide, and split water molecule into hydrogen [18, 22]. The $\mathrm{Bi}_{6} \mathrm{Fe}_{2} \mathrm{Ti}_{3} \mathrm{O}_{18}$ and $\mathrm{TiO}_{2}$ nanofibers are prepared by the electrospinning method. The diameters of the $\mathrm{Bi}_{6} \mathrm{Fe}_{2} \mathrm{Ti}_{3} \mathrm{O}_{18}$ and $\mathrm{TiO}_{2}$ nanofibers are $100-150 \mathrm{~nm}$ and $100 \mathrm{~nm}$, respectively. The load of $\mathrm{Au}$ nanoparticles into $\mathrm{Bi}_{6} \mathrm{Fe}_{2} \mathrm{Ti}_{3} \mathrm{O}_{18}$ increases the photocatalytic activity used in the ferroelectric devices like multi-state memory devices, field sensing and catalytic activities. From the $\mathrm{TiO}_{2}$ nanoparticles we can prepare nanorods, nanofibers, nanobelts and nanosheets. Among these nanostructures the nanofibers are being preferred because of high surface to volume ratio, excellent electron transfer, and charge transferability. The famous applications of the $\mathrm{TiO}_{2}$ nanofibers are in the top-gate fieldeffect transistor. If the cadmium nanoparticles are doped with the $\mathrm{TiO}_{2}$, then its morphological structure becomes tetragonal with the diameter size $200-330 \mathrm{~nm}$. These nanocomposites are used in the dye-sensitized solar cells [19-21]. The pendent thiol group grafed poly (3,4-proplenedioxythiophene) hallow nanofibers with diameter range 50-80 nm have an effective application in the electrocatalytic field and were prepared via surfactant-assistant method. These materials strengthen the electrochemical sensing ability due to their unique electronic transmission channels, effective molecular recognition ability and unique electrocatalytic properties [23]. The hydrogen peroxide $\left(\mathrm{H}_{2} \mathrm{O}_{2}\right)$ plays important role in the biological systems, the required or balanced quantity of hydrogen peroxide is to be maintained. Hence to identify the hydrogen peroxide in the biological system we need to undergo electrochemical methods. In this method electrochemical sensors have been employed or adopted to analyze $\mathrm{H}_{2} \mathrm{O}_{2}$. The $\alpha-\mathrm{MnO}_{2}$ nanorods grown on the NGNFs (nitrogen-doped graphite nanofibers) prepared by one-pot hydrothermal process with $130-170 \mathrm{~nm}$ diameter of nanorods and tetragonal structure are efficient electrochemical detectors of $\mathrm{H}_{2} \mathrm{O}_{2}$ [24]. The porous hydrogen manganese oxide (HMO) nanofibers play a vital role in the lithium recovery process from the seawater. The lithium is estimated in the sweater $2.5 \times 10^{14} \mathrm{~kg}$ which is very low percentage $(\sim 0.17 \mathrm{mg} / \mathrm{L})$ compared to other elements such as $\mathrm{Na}, \mathrm{Ca}, \mathrm{Mg}$, and $\mathrm{K}$. The recent studies and research have been concentrated on inorganic good adsorbent like highly porous hydrogen manganese oxide (HMO) nanofibers prepared via combining electrospinning, calcination, and ion exchanges. The HMOs will have cubic structure with diameter of $2-80 \mathrm{~nm}$ which have high capacity to absorb the lithium ions [25] (Table1).
Environmental hazardous are being increased in the globe due to the manmade and natural calamities. The chemical effluents are one of the major challenges to modern society and governments in the present context. Hence, the wastewater management is essential to scale down the hazardous outbursts. Some of the methods have been followed such as chemical oxidation, adsorption, photocatalysis, and membrane separation. Among these methods all are not cost effective and eco-friendly but photocatalysis is the cost-effective and greener technology with lower consumption energy. In the photocatalysis, the photocatalysts are the semiconductors with dopants or defect-induced or hybrid nanomaterials which can give higher photocatalytic action due to synergistic and plasmonic effect. The $\mathrm{ZnO}$ is $\mathrm{n}$ type semiconductor with nontoxicity, higher thermal and chemical stability with unique optical and photoelectrochemical properties. The $\mathrm{ZnO}$ has other important properties such as s high quantum yield and inherent surface defects which can sensitize under visible light. The most preferable nanostructure of $\mathrm{ZnO}$ is the nanofibers in this context as it provides high aspect ratio and a defined flow pattern for enhanced photocatalytic property. These nanofibers possess $800 \mathrm{~nm}$ of diameter with hexagonal structure prepared by electrospinning [26]. In the wearable electronics, stretchable and transparent conductors are essential to meet varieties of global demands without altering the resistance value. These conductors are made up of nanofibers Au metalized PVP prepared by sputtering which can withstand all types of mechanical deformations such as folding, twisting, bending, and stretching. These are synthesized in the form of nanofibers used in the memory parts of devices, electronic skins, electronic eye camera, and wearable health monitoring systems. The stretchable conductors are the important materials in stretchable electronics as they served as electrodes and interconnects in electronics system, particularly in optoelectronic devices along with stretchable solar cells, light emitting diodes, touch screens, and photodetectors [27]. The zinc oxide $(\mathrm{ZnO})$ nanoparticles play very important in the antibacterial and dye removal activates. The $\mathrm{Ag}, \mathrm{Cu}, \mathrm{TiO}_{2}$, and $\mathrm{ZnO}$ nanoparticles are being used in the antibacterial agents and among these $\mathrm{ZnO}$ is the most effective nanomaterial in this connection. The $\mathrm{ZnO}$ is also used in the dye removal process effectively because of excellent adsorption coefficient by virtue of its surface morphology and volume to surface ratio. Hence the zinc oxide nanoparticles attached to polyacrylonitrile nanofibers with hinokitiol as gluing agent for synergistic antibacterial activities and effective dye removal [28]. And the $\mathrm{ZnO}$ nanofibers are prepared by electrospinning used in the solar cells. The carbon particles nanofibers derived from the bio-waste or polymer are being used in the energy storage devices [29, 30]. The aluminum-based nanocomposites like $\mathrm{Al}_{0.2} \mathrm{La}_{0.8} \mathrm{TiO}_{3}$ are the new trends in 
the field of photocatalytic applications. These nanocomposites are prepared by the hydrothermal process and depending on the composition the structure can be changed which is observed based on the X-ray diffraction analysis. This compound $(1-x)\left(\mathrm{Al}_{0.2} \mathrm{La}_{0.8} \mathrm{TiO}_{3}\right)+(x)\left(\mathrm{BaTiO}_{3}\right)(x=$ $0.2-0.8)$ exhibits very good electrical properties and several advantages over other composites such as X-ray density $\left(\sim 11.210 \mathrm{~g} / \mathrm{cm}^{3}\right)$, surface area $\left(\sim 62.29 \mathrm{~m}^{2} / \mathrm{g}\right)$ electrical conductivity $(\sim 4.21 \mathrm{E}-05 \mathrm{~S} / \mathrm{cm}$ at $1 \mathrm{MHz})$ and dielectric constant of 62,768 at $1 \mathrm{kHz}$ [31]. The $\mathrm{TiO}_{2}$ nanofibers are prepared by electrospinning used in dye-sensitized solar cells as an anode material. The $\mathrm{TiO}_{2}$ based materials are cost-effective and eco-friendly in nature [32].

It was a well-known fact that nanorods played a vital role in gas sensor applications. Lingmin et al. [15], prepared the pure $\mathrm{ZnO}$ nanorods and $\mathrm{ZnO} / \mathrm{Ag}$ composite and showed the gas sensing performance. Especially, these devices exhibited the gas sensing activity for the $\mathrm{C}_{2} \mathrm{H}_{5} \mathrm{OH}$, carbon monoxide, nitrogen dioxide, and methane after subjecting them to UV radiation. Based on the surface morphological behavior of these two samples, the gas sensing behavior was identified. That is, as indicated in the FESEM pictures of $\mathrm{ZnO}$ nanorods (Fig. 6 [15]), the multiple junction positions were noticed between the clusters of nanorods. These junctions can act as potential barriers. Therefore, there will be a clear formation of electrons and holes at these junctions. In addition, the doping of $\mathrm{Ag}$ into the $\mathrm{ZnO}$ system induced the formation of barriers. Due to the smaller value of work function of $\mathrm{Ag}$ than the $\mathrm{ZnO}$, the electrons will be transferred easily from $\mathrm{Ag}$ portion to $\mathrm{ZnO}$ portion. Herein, the $\mathrm{Ag}-\mathrm{ZnO}$ interface can act as the Schottky barrier trapping the electrons coming from the conduction band of $\mathrm{ZnO}$. The resistance sensitivity response curves of both the samples were shown in Fig. 7 [15]. It was evident that the $\mathrm{ZnO}$ nanorods and $\mathrm{ZnO}$ nanorods/Ag nanofibers composites showed the gas sensing response under the UVradiation illumination of $365 \mathrm{~nm}$. Among these nanostructures, it was clear that the Ag nanofibers were acted as the barriers or bridge to the nanorods. Therefore, it was understood that the materials or composites possessing the nanorods/nanofibers like structures as well as the interface forces performed the efficient gas sensor applications.

In Fig. 8, it was observed that the $\mathrm{Pt} / \mathrm{WO}_{3}$ nanofibers performed the photoelectrocatalytic activity as a function of various Pt contents. Herein, the bandgap was noticed to be decreasing with increase of Pt content. This evidenced a fact that the Pt nanoparticles can act as the Schottky barrier which can utilize the visible radiation and reinforce the generation and transfer of electrons and holes [18]. In addition, the photodegradation of $\mathrm{RhB}$ solution under the visible light irradiation clearly showed that the $C / C_{\mathrm{o}}$ ratio (Fig. 9a) was noticed to be decreasing with increase of $\mathrm{Pt}$ concentration and time. However, for the $1 \%$ of $\mathrm{Pt}$, the photocatalytic activity was found to be high. This behavior was attributed to the uniform distribution of platinum nanoparticles on the surface of $\mathrm{WO}_{3}$ nanofibers and providing sufficient routes for electron transfer [18]. As a result, the $1 \% \mathrm{Pt} / \mathrm{WO}_{3}$ nanofibers offered the highest photocurrent density (Fig. 9b) as well as the smallest electrical resistance (high electrical conductivity) as compared with other samples. This was ascertained owing to the recombination of photogenerated carriers [18]. In Fig. 8c, the Nyquist plots of various concentrations of $\mathrm{Pt} / \mathrm{WO}_{3}$ nanofibers were shown and it was understood that the relaxations were of non-Debye kind. Besides, the complete arcs were not formed due to the partial relaxation strength of carriers, wherein the carriers can move for the longer distances. The excitation wavelength of $464 \mathrm{~nm}$ was observed in the photoluminescence spectra of $\mathrm{Pt} / \mathrm{WO}_{3}$ nanofibers (Fig. 8d). Especially, the low intensity was recorded for $1 \% \mathrm{Pt} / \mathrm{WO}_{3}$ nanofibers, wherein the separation efficiency of photoinduced charges was high [18]. It was confirmed that with the incorporation of $\mathrm{Pt}$ nanoparticles into the $\mathrm{WO}_{3}$ nanofibers, some advanced properties were obtained as discussed above. In Fig. 9, the pure titanium dioxide nanofibers showed low current density while the $1 \% \mathrm{Cd}$-doped titanium dioxide nanofibers offered the improvement of current density [21]. This indicated a fact that the moderate doping concentration of element induced the current density. This kind of manner was attributed to the photon-electricity conversion efficiency within the samples [21]. In reference [28], the antimicrobial activity was studied for $\mathrm{ZnO} /$ polyacrylonitrile nanofibers via the disk diffusion test method (Fig. 8a). It was clear that the inhibition zones were evidently noticed for $\mathrm{ZnO} /$ polyacrylonitrile nanofibers comprising of hinokitiol (HT) and zinc oxide $(\mathrm{ZnO})$. Herein, the antibacterial activity of samples was performed against Escherichia coli (E. coli) and Staphylococcus aureus (S. aureus). It was noticed that the HT-PAN-L, HT-PAN-H, ZnO-PAN-L, ZnO-PAN-H, ZnO-HT-PAN-L, ZnO-HTPAN-H (where PAN = polyacrylonitrile) offered a progressive inhibition zones against both bacterial strains (E. coli and S. aureus). These were shown in Fig. 9b, c. As a whole, it was confirmed that the combination of HT and $\mathrm{ZnO}$ induced stronger antibacterial activity against the $\mathrm{S}$. aureus rather than the E. coli [28]. For all the samples, the inhibition zones were expanded significantly on combing the $\mathrm{HT}, \mathrm{ZnO}$, and PAN against E. coli and S. aureus. However, the similar combination showed the larger expansion of inhibition zones against $\mathrm{S}$. aureus.

The electrochemical impedance spectroscopy (EIS) analysis of $\mathrm{Si} / \mathrm{TiO}_{2} / \mathrm{Ti}_{2} \mathrm{O}_{3}$-carbon (STTC) nanofiber composites and $\mathrm{SiC}$ (SC) nanofibers were performed along with electrochemical kinetics as indicated in Fig. 10 [34]. This analysis was done using the in situ EIS analysis. Particularly, the Nyquist plots of STTC and SC nanofibers were 

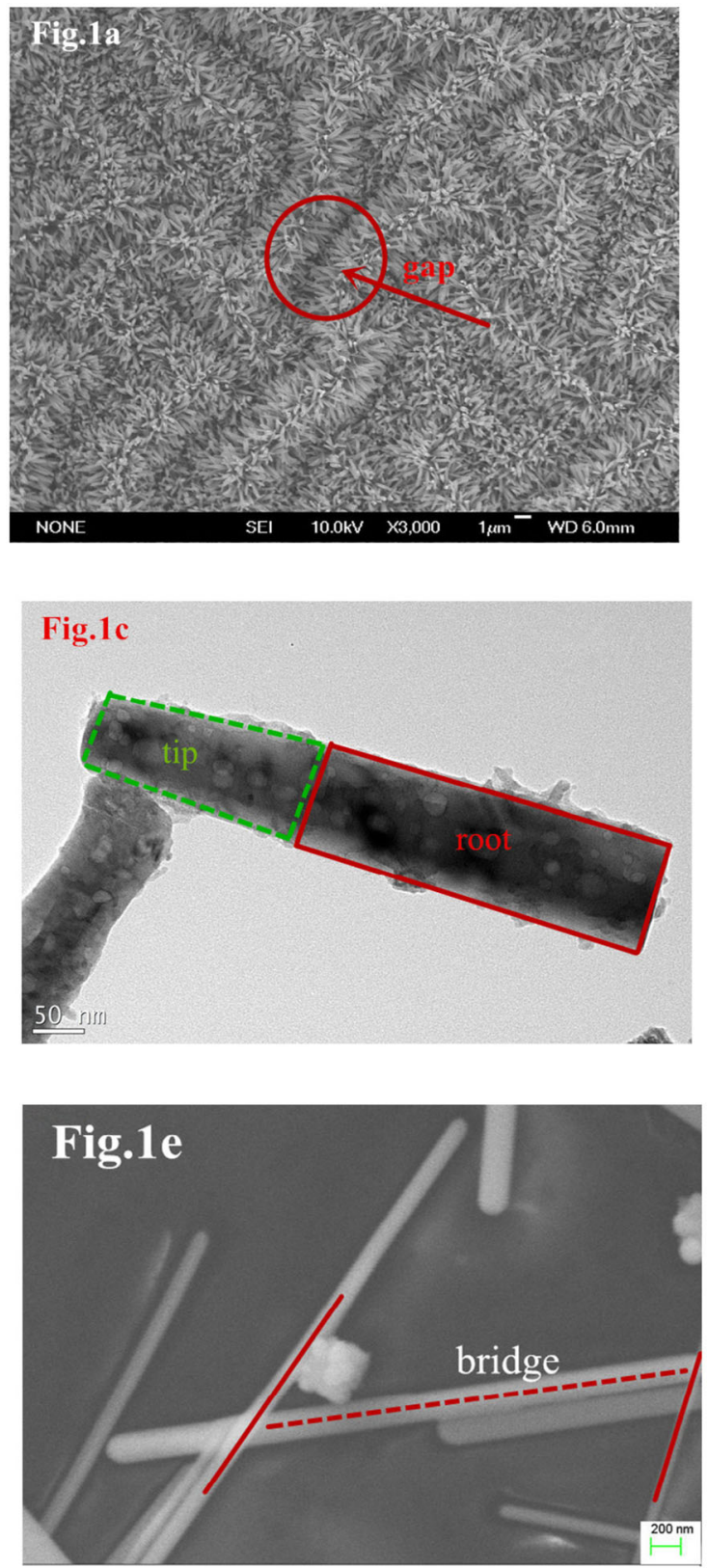

Fig. 6 Low magnification (a) and high magnification (b) SEM of hierarchically nanostructured $\mathrm{ZnO}$ nanorods. c TEM image from one $\mathrm{ZnO}$ nanorod. The inset in $\mathbf{c}$ is a selected-area electron diffraction

shown in Fig. 10d, e. Two kinds of semicircular arcs were seen indicating the high and mid frequency arcs. The high frequency arcs were related to the solid electrode interphase (SEI) impedance $\left(R_{\mathrm{SEI}}\right)$ while the mid frequency arcs were connected to the interphase charge transfer impedance $\left(R_{\mathrm{CT}}\right)$. It was also clear that the $R_{\mathrm{SEI}}$ of STTC and SC nanofibers was almost constant at high frequency arcs for the first discharge cycle, whereas after the first discharge, the $R_{\mathrm{SEI}}$ (Fig. 8a) of STTC and SC (Fig. 8b) approached to $45 \Omega$ and $90 \Omega$, respectively. The reason behind the constant trend of $R_{\mathrm{SEI}}$ can be attributed to the active particles which
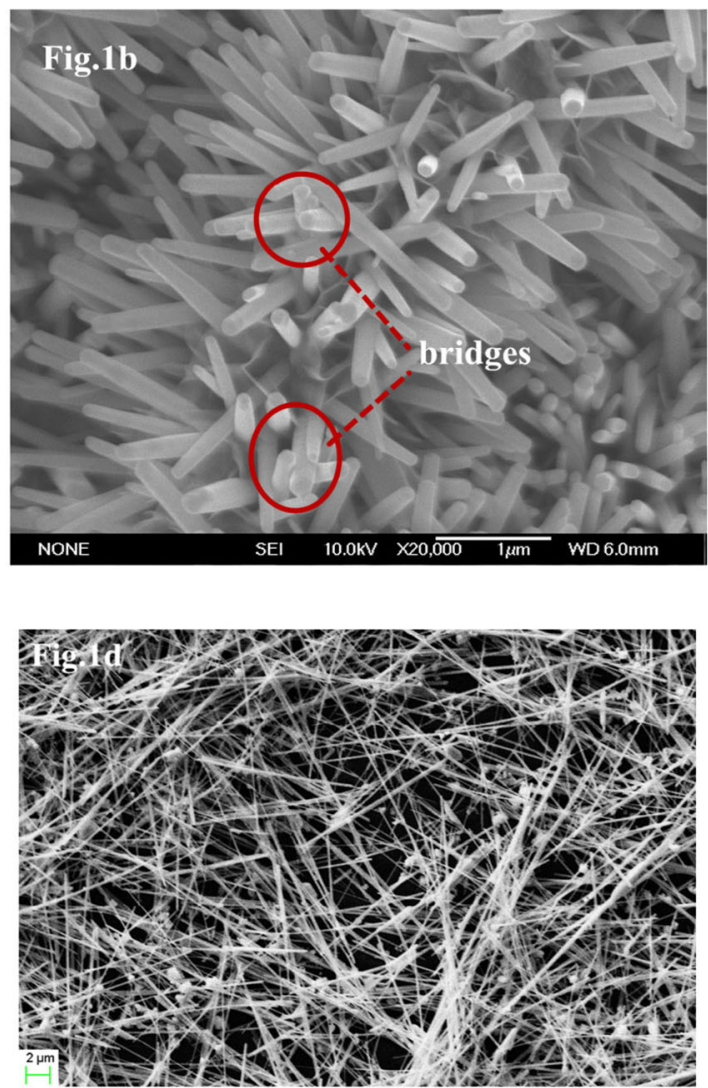

Fig.1f

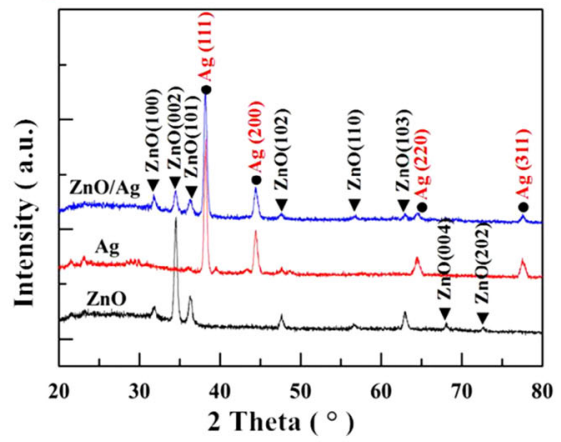

pattern. d SEM image of dense Ag nanofibers network. e Further magnified SEM image showing the bridging of Ag nanofibers. $f$ XRD from $\mathrm{ZnO}$ nanorods, $\mathrm{Ag}$ nanofibers, and $\mathrm{ZnO} / \mathrm{Ag}$ composites [15]

were perfectly coated by carbon nanofibers and therefore, it can reduce the evolution of SEI. Similarly, after first discharge, the surface of $\mathrm{Si} / \mathrm{TiO}_{2} / \mathrm{Ti}_{2} \mathrm{O}_{3}$ and $\mathrm{Si}$ offered highcapacity retention and cyclic stability [34]. In addition, it was also noticed that for STCC, the $R_{\mathrm{SEI}}$ was almost constant while for SC, it was varied. The reason was the presence of titanium which works as buffer. But for $\mathrm{Si}$, there was no buffer element. It was understood that the nanofiber structures and titanium buffer played a vital role in increasing the capacity retention and cyclic stability. Therefore, the STTC and SC were largely useful for the 


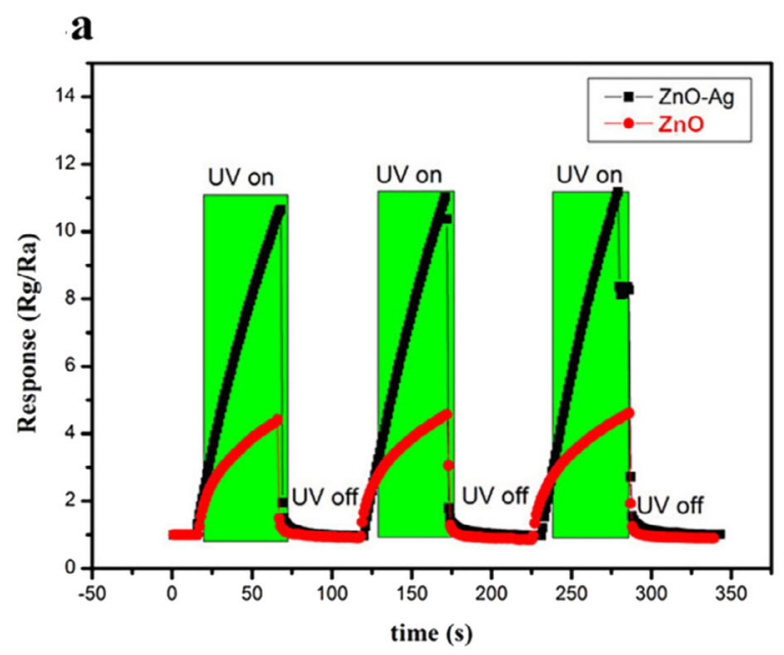

\section{b}
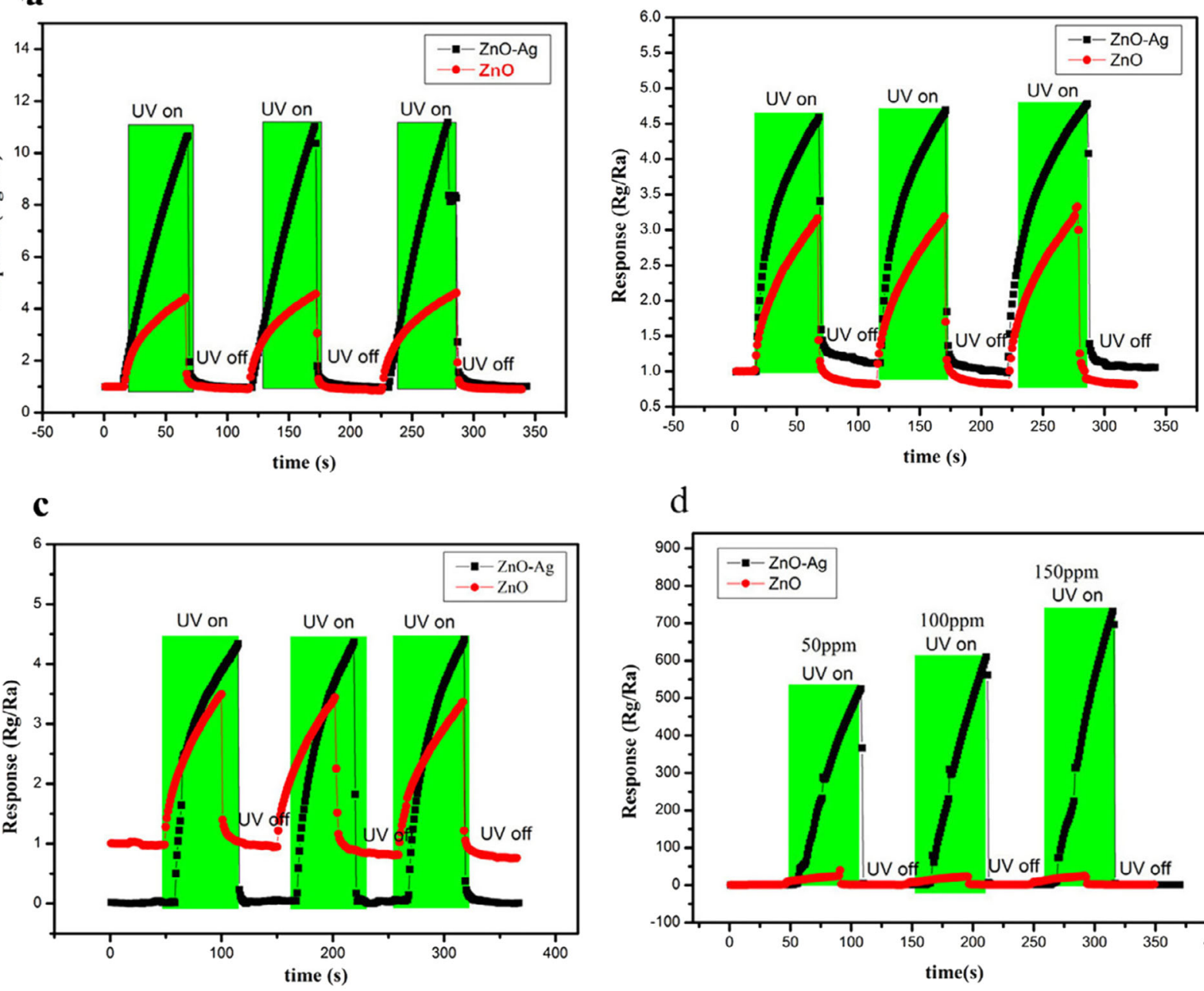

d

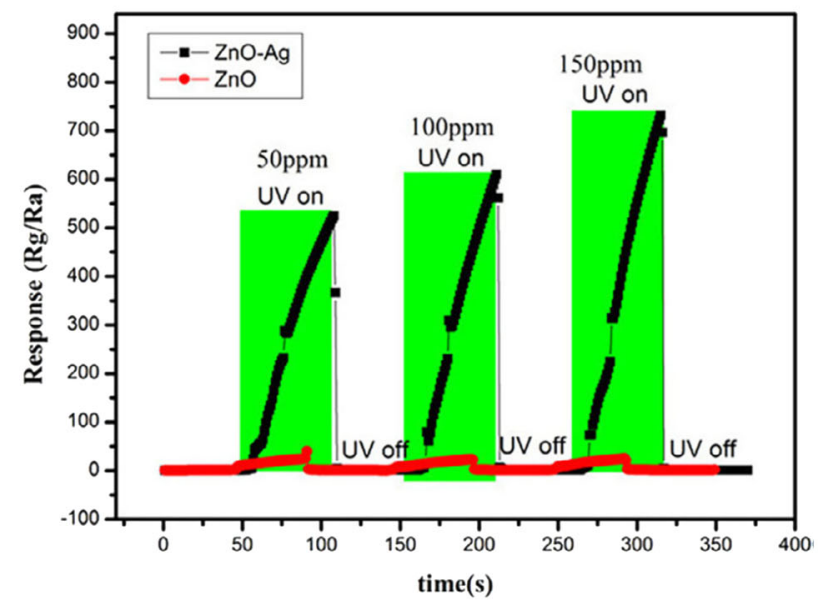

Fig. 7 Response curves of the $\mathrm{ZnO}$ and $\mathrm{ZnO} / \mathrm{Ag}$ composites upon exposure to $50 \mathrm{ppm}$ of $\mathbf{a ~} \mathrm{CH}_{4}, \mathbf{b} \mathrm{CO}$, and $\mathbf{c}$ ethanol, $\mathbf{d}$ different concentrations of $\mathrm{NO}_{2}$ under $365 \mathrm{~nm}$ UV Illumination [15]

lithium-ion batteries applications [34]. To understand the diffusion of lithium ions in the $\mathrm{Ti}_{2} \mathrm{O}_{3}$, the diffusion coefficient (DC) was computed with the help of DFT and molecular dynamics model. The mean square displacement against the time $(t)$ plots (Figs. 11, 12) indicated that the DC of lithium ions in titanium dioxide showed $10^{-12} \mathrm{~cm}^{2} / \mathrm{s}$ [34]. In addition, it evidenced that the $\mathrm{Ti}_{2} \mathrm{O}_{3}$ was developed in the surface portion of titanium dioxide. It became conductive to the transmission of lithium ions inside the silicon domains [34]. Fig. 11 indicates the diffusion energy barrier based on density functional theory calculation, and Mean-squared displacements of $\mathrm{Li}$ ions in $\mathrm{Ti}_{2} \mathrm{O}_{3}$, and linear fit curve.

In Fig. 12, the electrochemical behavior of reduced graphene oxide (RGO) coated $\mathrm{Sb}_{2} \mathrm{~S}_{3}$ nanorods was depicted [40]. Especially, Fig. 12a provides the cyclic voltammetry curves of RGO coated $\mathrm{Sb}_{2} \mathrm{~S}_{3}$ nanorods for a step scan of $0.1 \mathrm{mV} / \mathrm{s}$. It was found that the three reduction peaks were noticed at four voltages as indicated in Fig. 12a for the first cycle. This indicated the first discharge energy process. But on the other hand, the peaks were formed which were of relatively similar trend for all the next cycles. Herein, the formed two peaks were related to the reductive (at $0.85 \mathrm{~V}$ ) and alloying (at $0.42 \mathrm{~V}$ ) reactions. These anodic peaks were evolved owing to the reversible formation of $\mathrm{Sb}_{2} \mathrm{~S}_{3}$ [40]. Similarly, the charge-discharge curves of RGO coated $\mathrm{Sb}_{2} \mathrm{~S}_{3}$ nanorods (at specific density $=100 \mathrm{~mA} / \mathrm{g}$ ) showed two plateaus indicating the reductive and alloying reactions [40]. In addition, it was confirmed that the pure nanorods and RGO decorated nanorods showed the almost identical voltage performances. From Fig. 12c, it was clear that the pure $\mathrm{Sb}_{2} \mathrm{~S}_{3}$ nanorods offered low-rate capabilities as compared to RGO decorated nanorods. The discharge capacity was decreased to $214 \mathrm{mAh} / \mathrm{g}$ at $2 \times 10^{3} \mathrm{~mA} / \mathrm{g}$ current density [40]. This evidenced a fact that the nanorod performance was increased little bit on coating it by RGO. The cyclic performance of RGO decorated nanorods showed 
Fig. 8 Photodegradation of RhB solution under visible-light irradiation (a), transient photocurrent responses (b), EIS Nyquist plots (c), and PL spectra (d) of $\mathrm{Pt} / \mathrm{WO}_{3}$ nanofibers with different Pt contents [18]
Fig. 9 a Representative images of inhibition zones, $\mathbf{b}$ and c Calculated inhibition zones of nanofibrous samples based on disk diffusion test with standard deviations against E. coli and S. aureus [28]
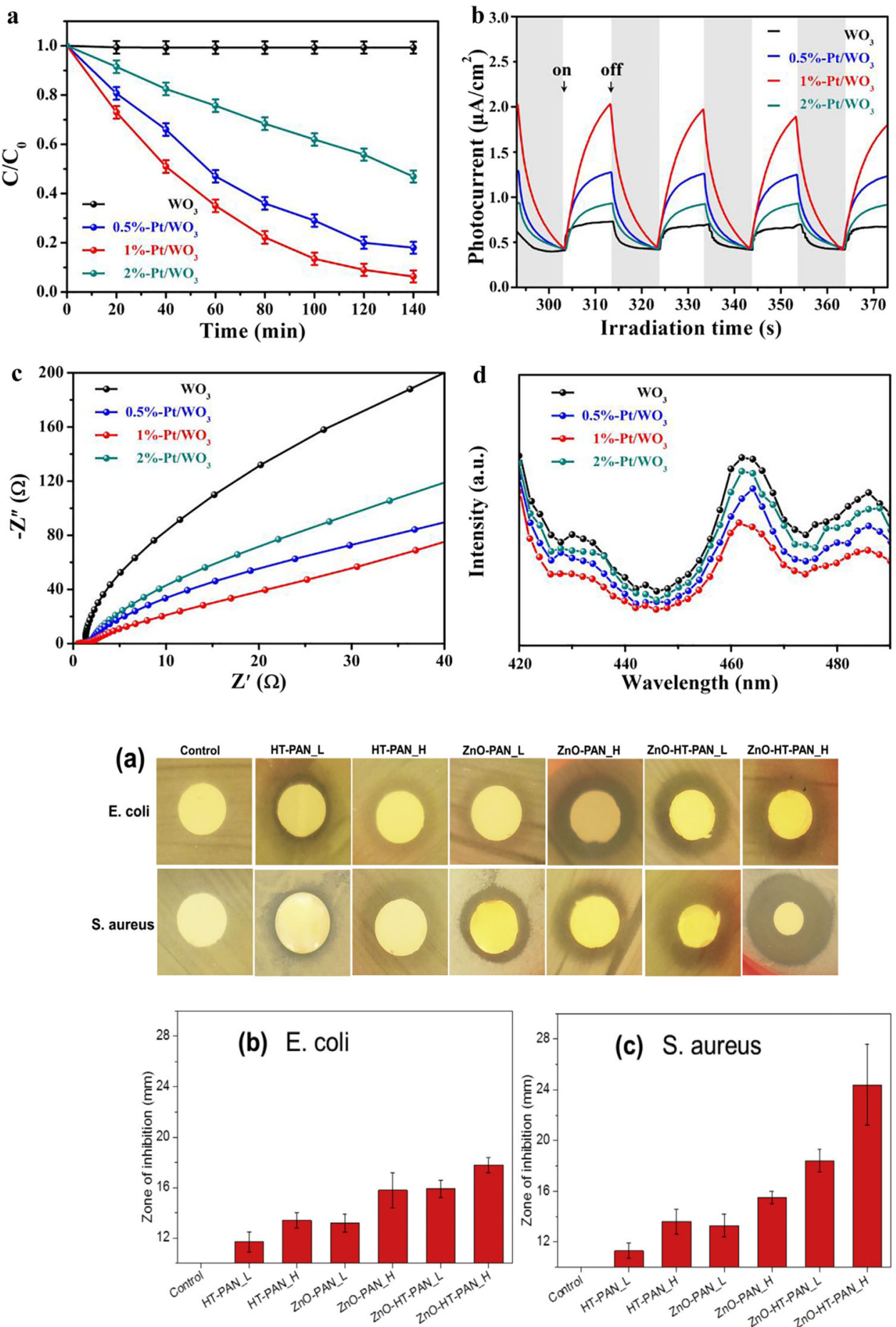

high specific capacitances as compared with the pure nanorods at high cycles (Fig. 12d). For instance, the RGO decorated nanorods provided the discharge capacity up to $652 \mathrm{mAh} / \mathrm{g}$ after 60 cycles [40]. This alone revealed the improvement of discharge capacitance of RGO decorated nanorods rather than the pure nanorods. Therefore, the present materials were useful for the sodium ion batteries [40].
In Fig. 13, it was seen that the composite nanofibers were prepared via different steps. That is, the PVDF pellet was coated with KNN nanorods powder of $0-6 \%$, wherein the acetone was used as a dispersing agent [57]. The resultant pellets were kept in a twin-screw extruder. In Fig. 13a, the key parameters and processing conditions were clearly mentioned. As a result of these parameters and maintained conditions, the melt spun monofilaments were developed 
$(a)_{50}$

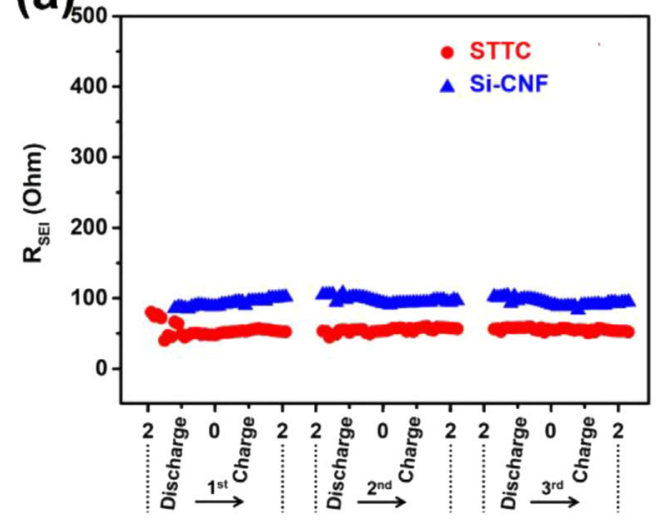

(c)

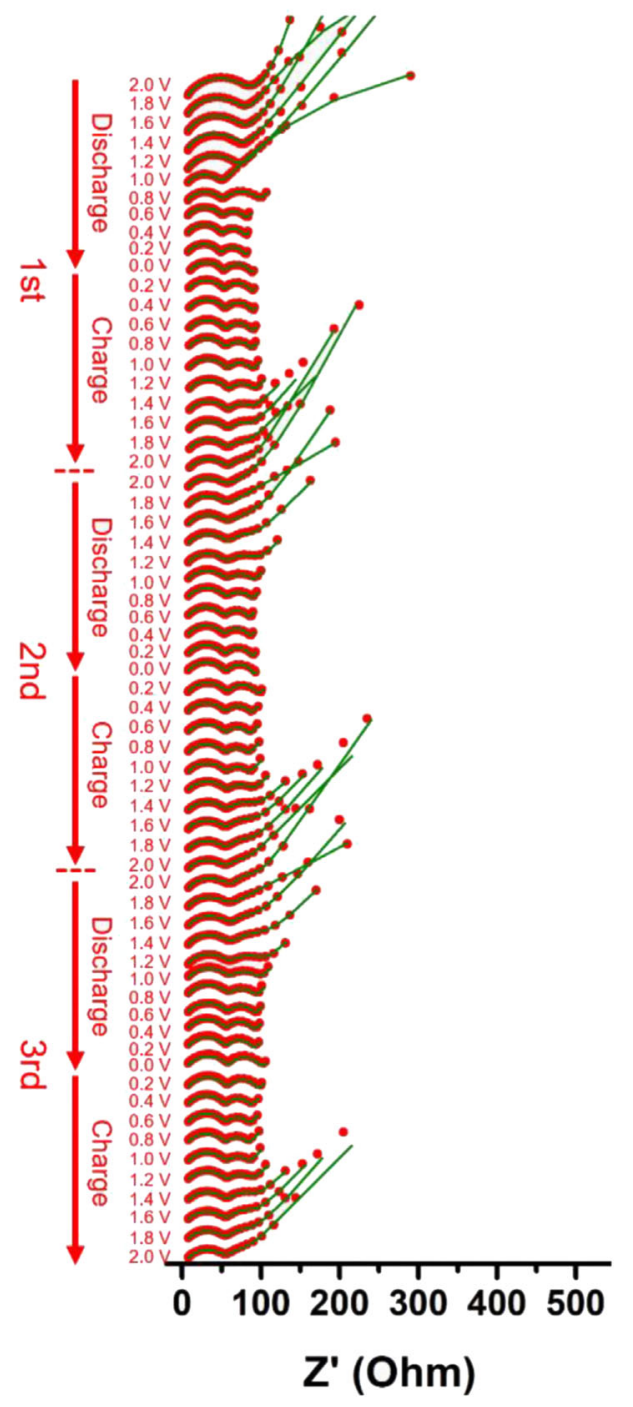

Fig. 10 In-site SEI and Li-ion intercalation/de-intercalation in STTC and SC: fitted results of a solid electrolyte interface resistance (RSEI) and $\mathbf{b}$ charge-transfer resistance (RCT) simulated from the Nyquist (b)

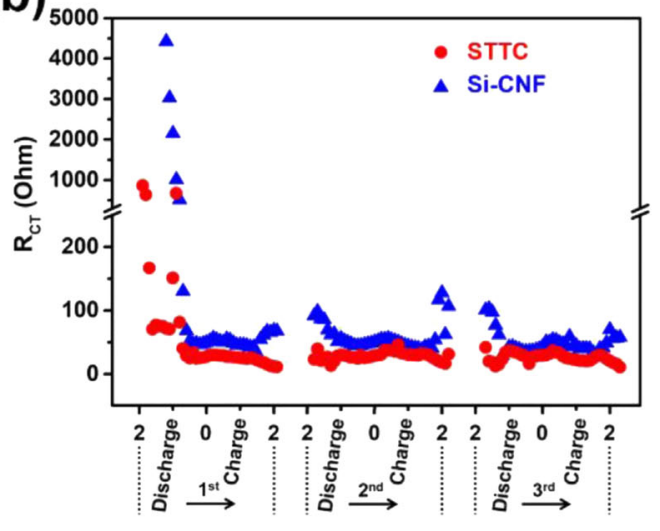

(d) $\triangle \mathrm{sc}$
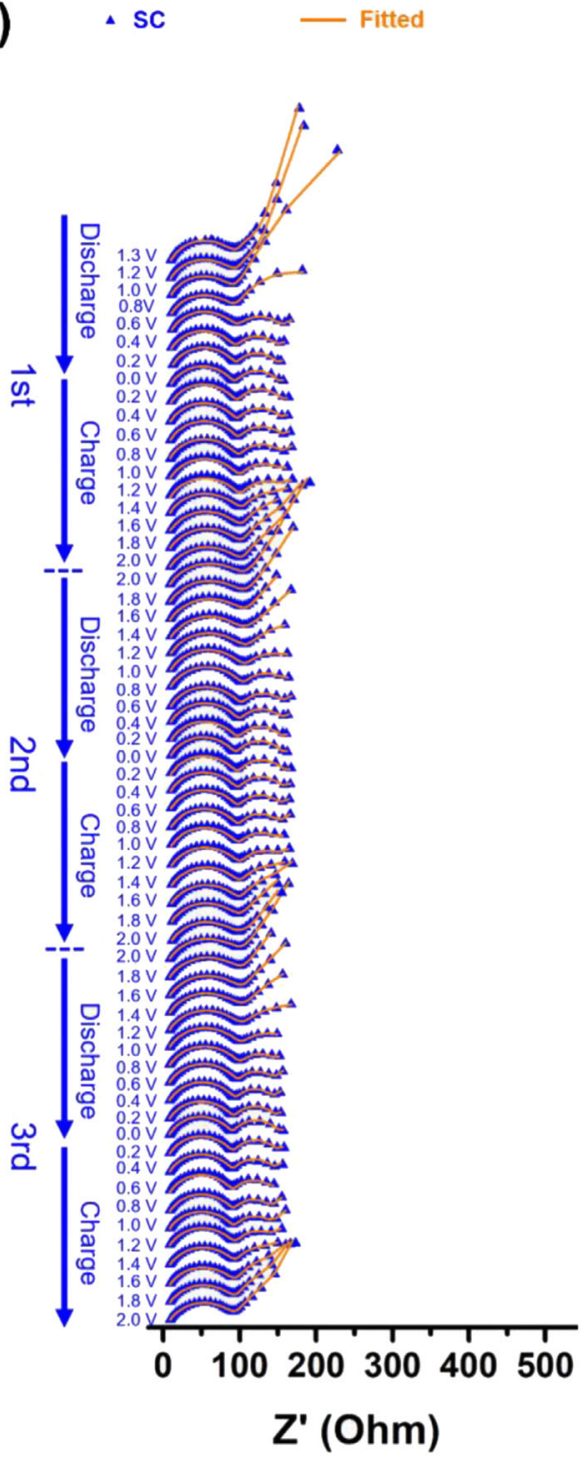

plots. The $x$-coordinates in Fig. $6 \mathrm{a}$ and $\mathrm{b}$ represent voltage. Nyquist plots from in-situ EIS of $\mathbf{c}$ STTC and d SC electrode with the fitted curves calculated by the equivalent circuit shown in Fig. S14 [34] 
(a)
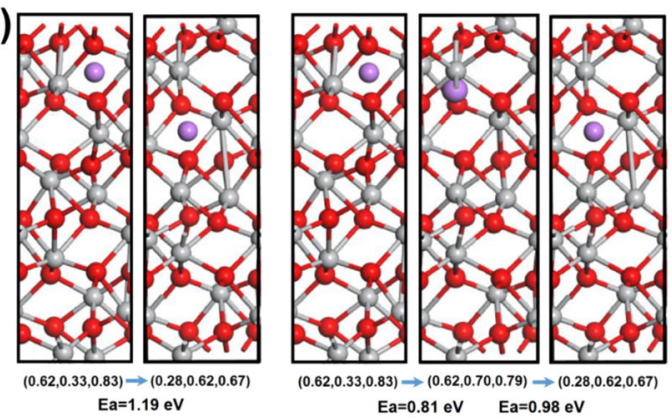

(b)

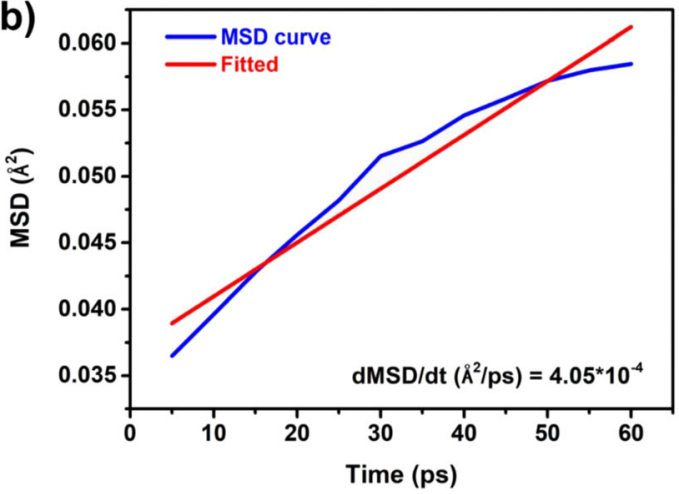

Fig. 11 a Diffusion energy barrier based on density functional theory calculation, b Mean-squared displacements of $\mathrm{Li}$ ions in $\mathrm{Ti}_{2} \mathrm{O}_{3}$, and linear fit curve [34]

having an average thickness of $1 \mathrm{~mm}$. Further, these filaments were kept nearer to the conductive aluminum tape for poling activity within the corona poling unit as shown in Fig. 13b. In addition, the poling was performed to the nanofilaments at $80^{\circ} \mathrm{C}$ temperature for the DC voltage of $15 \mathrm{kV}$ [57]. The piezoelectric behavior of nanogenerator prepared using different concentrations of KNN nanorods in PVDF pellets was provided in Fig. 14 [57]. Once the device was tapped using the finger, the output voltage can be found in the voltmeter. That is, if the force is applied on the surface of nanogenerator, the charge carriers will be away from their original positions and hence, they reach the top and bottom portions of the electrodes within the nanogenerator. Therefore, it develops a potential difference resulting the output voltage in the device. This voltage will be usually measured using the digital oscilloscope as mentioned in the reference [57]. The results ensured that the PVDF/4\% KNN NRs filament based nanogenerator performed the highest output voltage of $3.7 \mathrm{~V}$ as compared with other concentrations. From the analysis, it was confirmed that the nanorods exhibited the piezoelectric behavior by producing certain output voltage. Thus, one can use these nanorods based materials for piezoelectric device applications [57]. In Figs. 15 and 16, the growth of tumor after treatment against the tumor volume was depicted. The antitumor efficiency of prepared nanofibers can be well understood using this experiment [77]. It was evident that the pure nanofibers have not showed much cytotoxicity on the cancer cells. At that time, even the tumor volume was increased to larger extent. Furthermore, the gold nanoparticles were added to the nanofibers and then the tumor growth volume was little bit reduced. This indicated a fact that the introduction of gold nanoparticles into the nanofibers allowed the cancer treatment as well. In addition, the magnetic field was applied to the system consisting of nanofibers plus gold nanoparticles. As a result of this, the growth of the cancel cell was come down to smaller extent. It was concluded that the additive species within the mixture reinforced reducing the tumor volume growth 18-20 days after treatment [77]. Fig. 16 shows the cell culture results: absorbance of different materials through 1,3 , and 5 days of incubation.

The nanofibers and nanorods are one dimensional nanomaterial which will have variety of applications in the medical or medicine field such as drug delivery, Cell patterning, cell differentiation, cell cluster formation, and biosensor. The structure itself is supplementary to the transportation in tubular structures of nanorods.

\subsection{Bone tissue regeneration}

High porous electro spun hollow titania $\left(\mathrm{TiO}_{2}\right)$ nanofibers can be used in the bone tissue engineering [122]. $\mathrm{TiO}_{2}$ is one of the best nanomaterials in connection with biocompatibility due to its geometry, high aspect ratio and preserving the specific surface area on the level of reasonable porosity. In the bone, predominant inorganic material is the $\mathrm{CaCO}_{3}$ and calcium phosphate compounds. Due to emergence of 3D printing technology, which is coupled with computer-based CAD program, the artificial bones can be prepared. In the bone printing process, the mere calcium phosphate compounds do not give much mechanical strength as they are very low brittle in nature hence, we must add some nanoceramics into slurry to obtain high mechanical strength. The common ceramic materials are alumina, zirconia, and titanium. The titanium-based nanocomposite is superior for joint prostheses due to their appropriate compressive strength and biocompatibility than other ceramics. In terms of nano topographic effects on bone cell behaviors, $\mathrm{TiO}_{2}$ materials with various nanostructures display improved effects on development of bone tissue and bone regenerating capability. And the $\mathrm{TiO}_{2}$ nanotubes are expected to exhibit bone regeneration in medicine field and due to its porosity interaction between tissue and bone can be attained and achieve the transportation of the biomolecule between bone and tissue. Hence, the $\mathrm{TiO}_{2}$ supported hollow porous nanotubes functionalized with bioactive calcium salt might be a promising biomaterial for hard tissue replacement. The fabricated $\mathrm{TiO}_{2}$ immobilized cellulose acetate electro spun fibers prepared by electrospinning can be used in the photocatalytic 

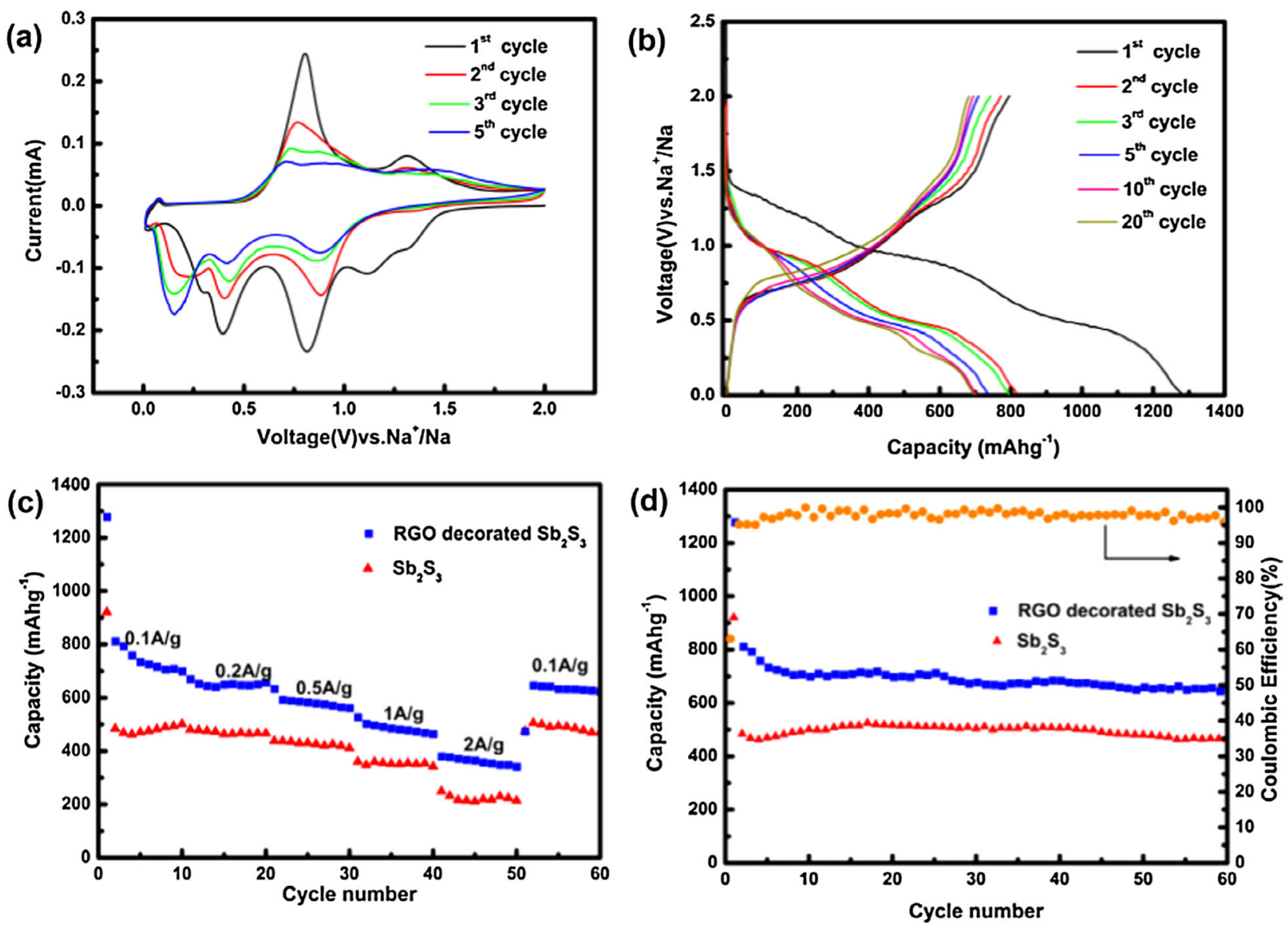

Fig. 12 a CV curves of the first five cycles of RGO decorated $\mathrm{Sb}_{2} \mathrm{~S}_{3}$ nanorods, $\mathbf{b}$ galvanostatic charge-discharge profiles of RGO decorated $\mathrm{Sb}_{2} \mathrm{~S}_{3}$ nanorods, $\mathbf{c}$ rate capability of $\mathrm{Sb}_{2} \mathrm{~S}_{3}$ and RGO decorated $\mathrm{Sb}_{2} \mathrm{~S}_{3}$

degradation of textile effluents like methylene blue. The higher photocatalytic activity of fibers was discerned with high $\mathrm{TiO}_{2}$ content as CA composite ultrafine fibers with $5 \mathrm{wt} \% \mathrm{TiO}_{2}$ were as high as $90 \%$ after $4 \mathrm{~h}$ of degradation $[122,123,124]$. It was also known that the proper combination of implant, and bone interface can become the vital aspect for implantation. In Fig. 17, the cell culture of various materials at various time intervals. The maximum absorbance of cell proliferation of hydrous titanium dioxide $\left(\mathrm{HTiO}_{2}\right)$ was noticed from 1 to 5 days. In addition, the sulphonated titanium dioxide $\left(\mathrm{STiO}_{2}\right)$ achieves the minimum absorbance for 5 days. However, the $\mathrm{HTiO}_{2}$ performed the good cell response at the end of incubation period. Further, it was also clear that the toxicity was completely reduced. Figure 18 was recorded to confirm the absorbance test. These micrographs show the cell morphology after incubation period. Herein, the minimum biocompatibility was observed in case of $\mathrm{STiO}_{2}$ nanofibers possessing the rounded cells. On looking at the performance of carbonated titanium dioxide $\left(\mathrm{CTiO}_{2}\right)$ nanofibers, it was evidenced that these nanofibers revealed the significant cell spread rather than the $\mathrm{STiO}_{2}$ nanofibers. Moreover,

nanorods, $\mathbf{d}$ cycling performances at $100 \mathrm{~mA} / \mathrm{g}$ of $\mathrm{Sb}_{2} \mathrm{~S}_{3}$, and RGO decorated $\mathrm{Sb}_{2} \mathrm{~S}_{3}$ nanorods [40]

comparatively, for $\mathrm{HTiO}_{2}$ nanofibers, the cell spread was improved with some dead cells on cell culture. The $\mathrm{HTiO}_{2}$ nanofibers showed good biocompatibility by providing the high cell spread due to the porous and hollow structure. Therefore, it can be well understood that the above strategies can improve the bone regeneration as well.

\subsection{Micropatterning technology in druyg delivery system}

This technology is widely being used in the medicine field, where micropatterned nanofibrous can be used as scaffolds for biomedical application. This technology plays a vital role in the controlling surface microenvironment, cell-cell, and cell-tissue interaction. The micropatterning techniques are mainly based on surface chemistry (generation of patterns which consists of chemically different micro-domains) and micro-patterned areas (generated by physical barriers). Conventionally the micro patterns have been prepared by the photo or soft lithography. The micro-pattern and Electro spun nanofibers extensively have been used in the drug delivery system. Micro-structured and electro spun 
Fig. 13 a Flow chart for meltspun filament production and fabrication of nanogenerator and b Poling process of the meltspun filaments [57] (a)

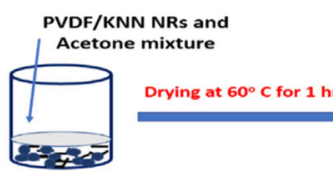

PVDF coated with
KNN NRs powder
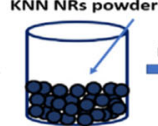

Filament formation Parameters: Mixing time- $10 \mathrm{mi}$ and $\mathrm{rpm}-100$
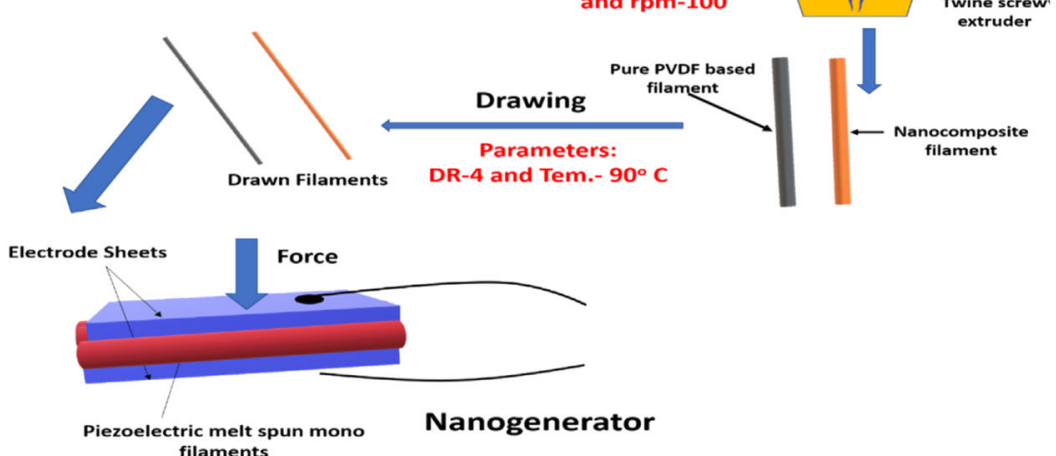

filaments

(b)

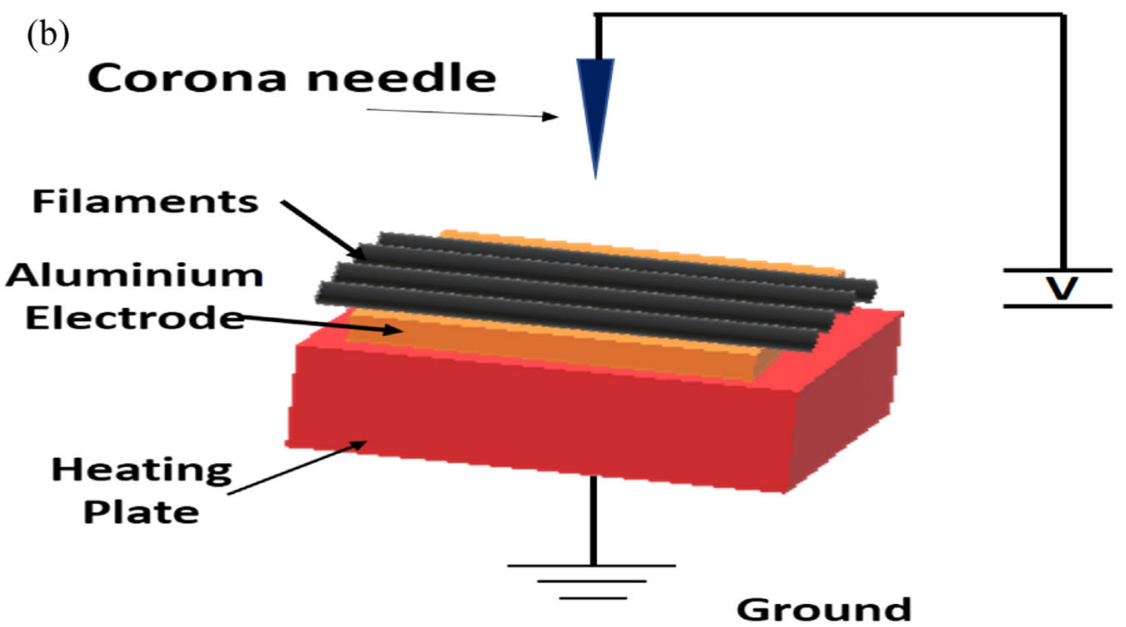

materials have large surface area which reduces the toxicity, enhanced drug encapsulation and increases the efficiency of delivery to the target. However, the behavior of drug delivery depends on the nature of the structure and reported that sustainable drug release can be achieved in nanofiber alignment and patterned fibrous scaffold. The release rate of fenbufen is slower in aligned Polylactic-co-glycolic acid/ chitosan nanofibrous scaffolds compared to random fibers. The decrease of pore size in the aligned nanofibers reduces the delivery or diffusion rate than that of random fibers. Micro-structured cellulose acetate nanofibers by nylon mesh with $50-100 \mu \mathrm{m}$ dimension openings showed a zero-order sustained drug release up to $12 \mathrm{~h}$ compared to nonpatterned scaffolds. The relevant reason is that minimization of solidliquid interface and higher angle of contact controls the drug release. The hydrophobicity (depends on the nanofiber density and distribution pattern) of the substrate also alters the drug release. Polyvinyl butyral mesh patterns showed slower drug release due to the even distribution of nanofibers and higher contact angle. Multicompartmental fiber matrix and hydrogel microparticle were evaluated for the sustainable growth factor release [123].

\subsection{The cell differentiation}

The cell differentiation is one of the biological processes which depend on the many factors such as diffusible molecules, cell-cell interactions, cell-matrix interaction etc. The cell fate is affected by many factors including surface topography, surface chemistry, etc. The nanofiber orientation and micropatterned structure plays important role in the tissue engineering. The micropatterned polyethylene glycol hydrogel with gelatin fiber was considered for osteogenic differentiation. Fiber attached by MSC will be differentiated into osteogenesis due to two reasons such as sustained release of basic fibroblast growth factor and bone morphogenetic protein 2 up to 4 days and 4 weeks from the fiber and PEG hydrogel. The staining plays the crucial role in the osteogenesis differentiation due to the presence of alkaline phosphatase and alizarin red. Su- 8 micropatterned 

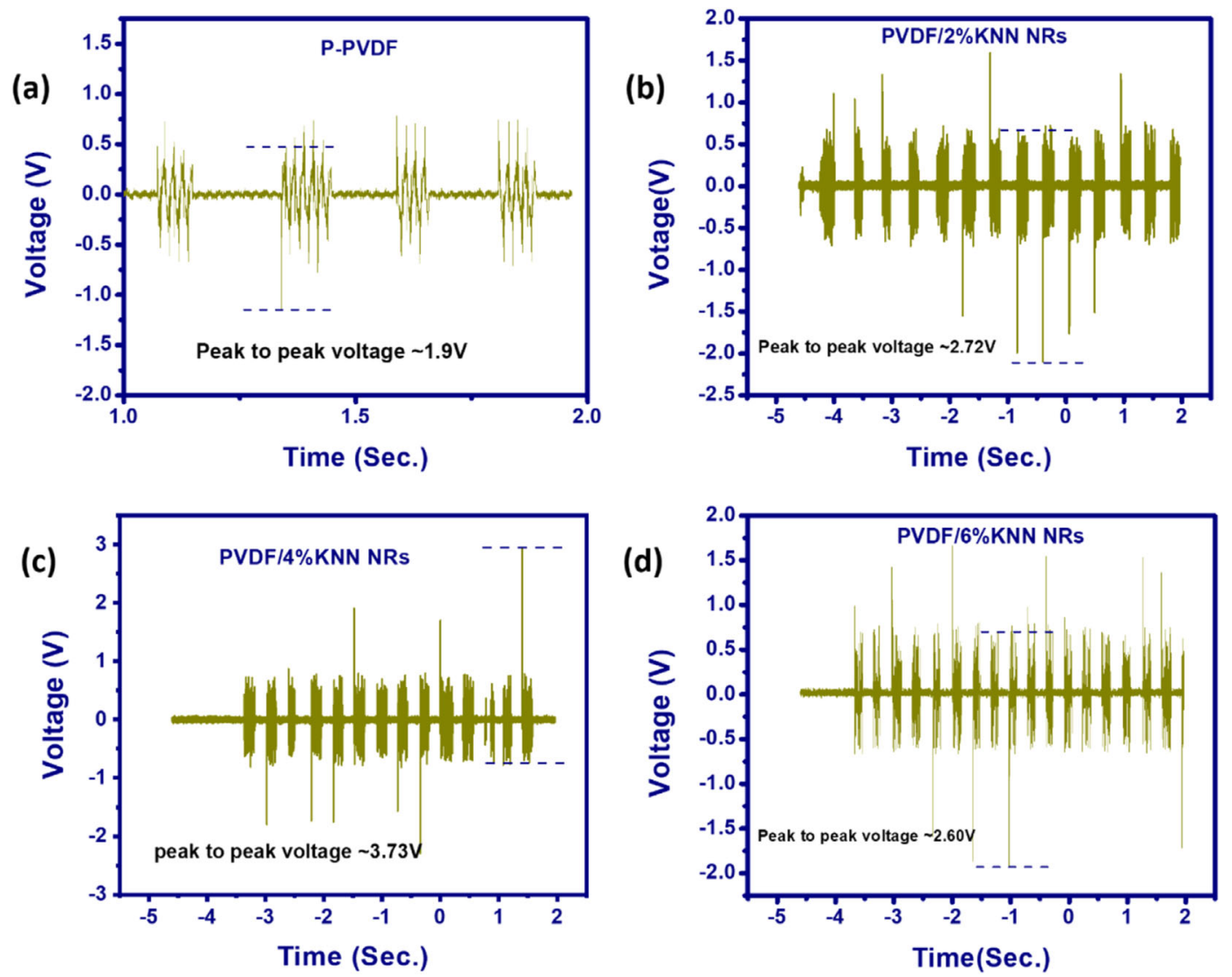

Fig. 14 a Output voltage signal for the P-PVDF filament based nanogenerator, b Output voltage signal for the PVDF/2\%KNN NRs filament based nanogenerator, c Output voltage signal for the PVDF/

$4 \% \mathrm{KNN}$ NRs filament based nanogenerator, and d Output voltage signal for the PVDF/6\%KNN NRs filament based nanogenerator [57]

Fig. 15 Tumor growth after treatment by the synthesized fibers [77]

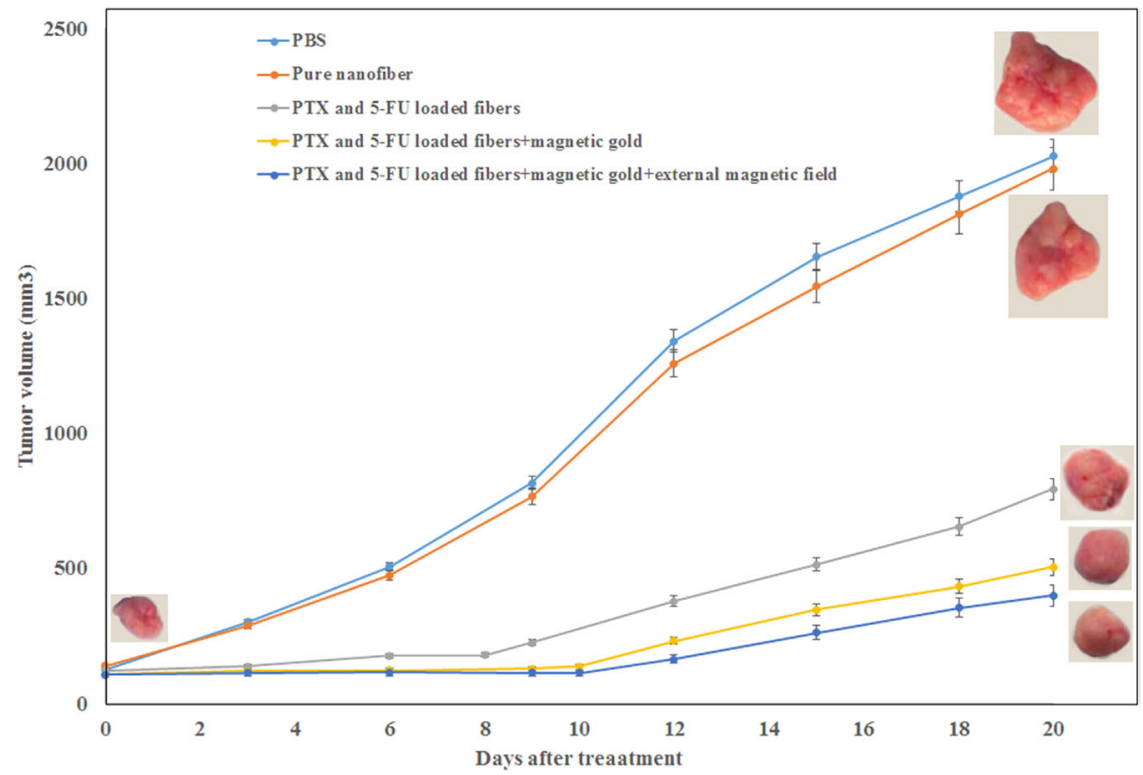

nanotube of $20 \mu \mathrm{m}$ dimension and grooved can induce selfearly osteo differentiation without any external agencies. The cells rotate and align along the patterns with the respect to time. The three-dimensional nanofibers surface fabricated by cylindrical collector is twice greater than that of twodimensional surfaces. Due to higher pore size in the threedimensional nanofiber the cell infiltration and migration are higher. In addition, this scaffold showed osteogenic 
Fig. 16 Cell culture results: absorbance of different materials through 1,3 , and 5 days of incubation [122]

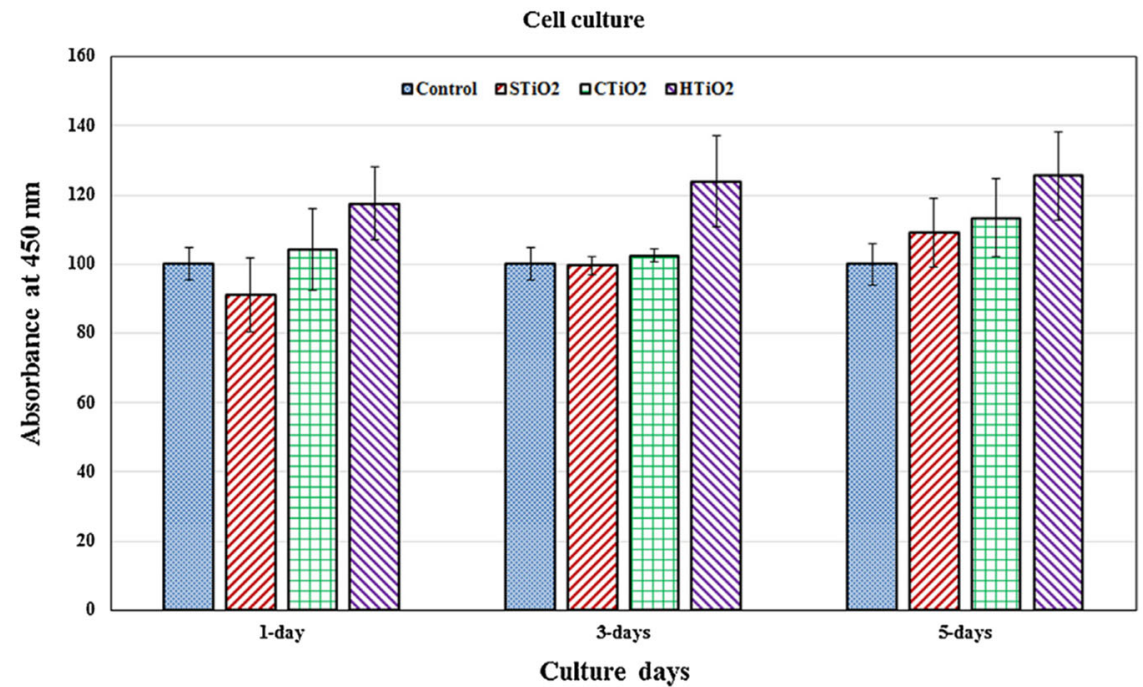

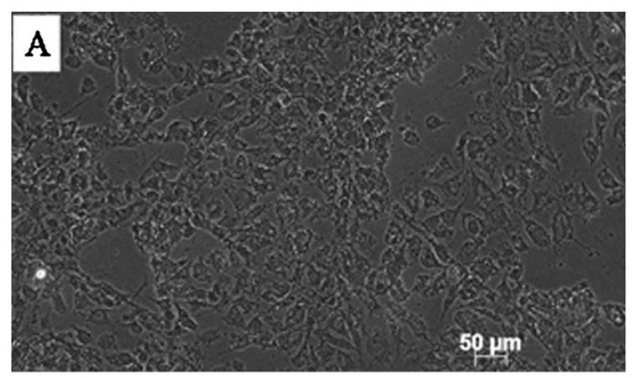
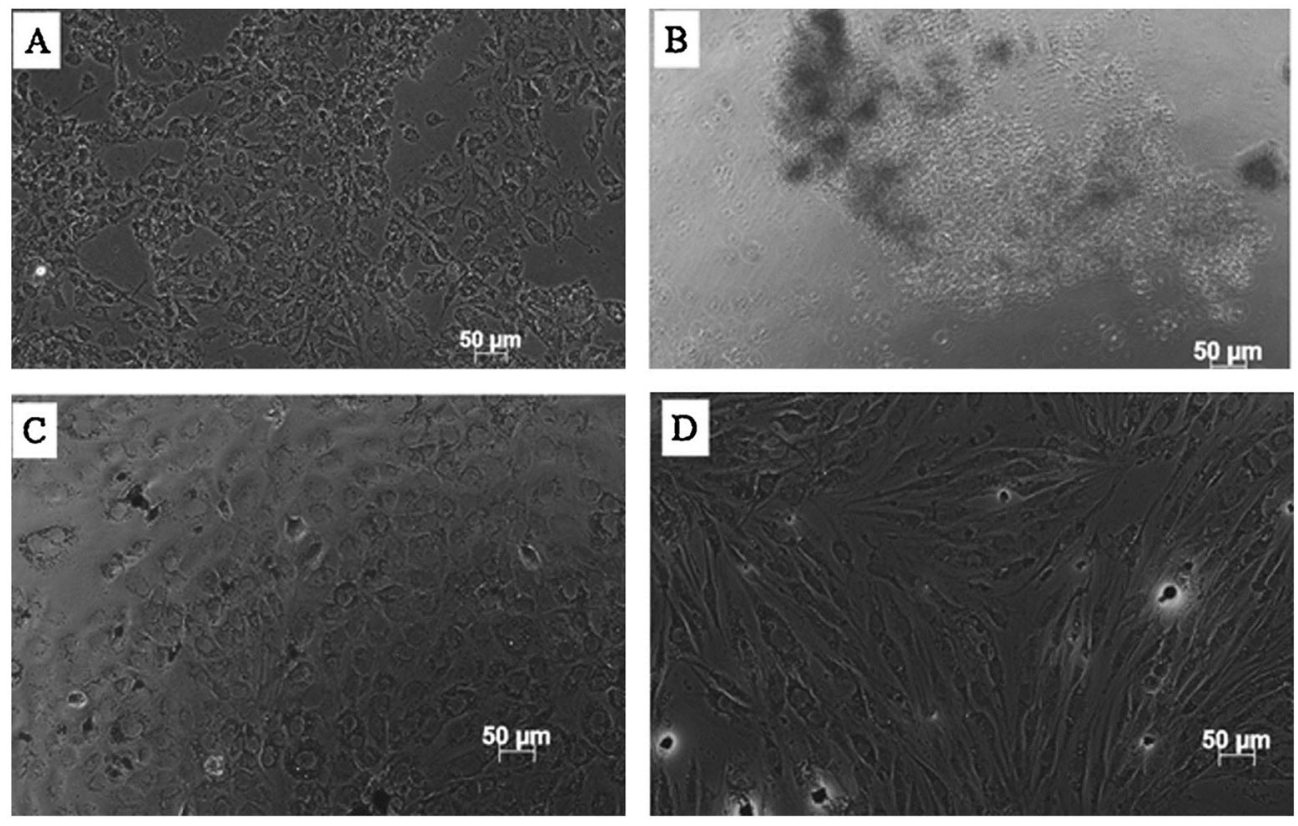

Fig. 17 Microscopic cell morphology/proliferation after five days of incubation for a control, b $\mathrm{STiO}_{2}, \mathbf{c} \mathrm{CTiO}_{2}$, and d $\mathrm{HTiO}_{2}$ [122]

differentiation, which is correlated with the cell adherence, flattening, and spread. The patterned, Polycaprolactone nanofiber mesh which is from conducting wire net collector is reported as one of the best osteogenic differentiations in human bone marrow stromal cell [123, 124]. In Fig. 18, the schematic representation of nanofiber membrane preparation, micrographs, and the extended behavior of fluorescence image of DRG neurites after 6 days were provided (Fig. 19).

\subsection{Electro spun nanomaterials}

These fibers will have different applications which are obtained from bio-macromolecules from botanical sources, polysaccharides from seaweeds, and polysaccharides from animal sources. The cellulose, starch and pectin are the biomacromolecules and from these electrospinning patterns can be prepared by Electrospinning method. The cellulose is one of the good renewable biomaterial ecofriendly good mechanical strength and biocompatibility. And it has excellent ecological credentials with potential medical, pharmaceutical, paper production, sanitary products, rayon, cellophane derivatives, textile fibers, medical fabrics, and industrial applications. The major cellulose sources are the cotton, wood pulp and other pulps. The cellulose extracted from both plants and bacteria in the form of nanomaterials will have uniqueness over the microstructures vowing to 


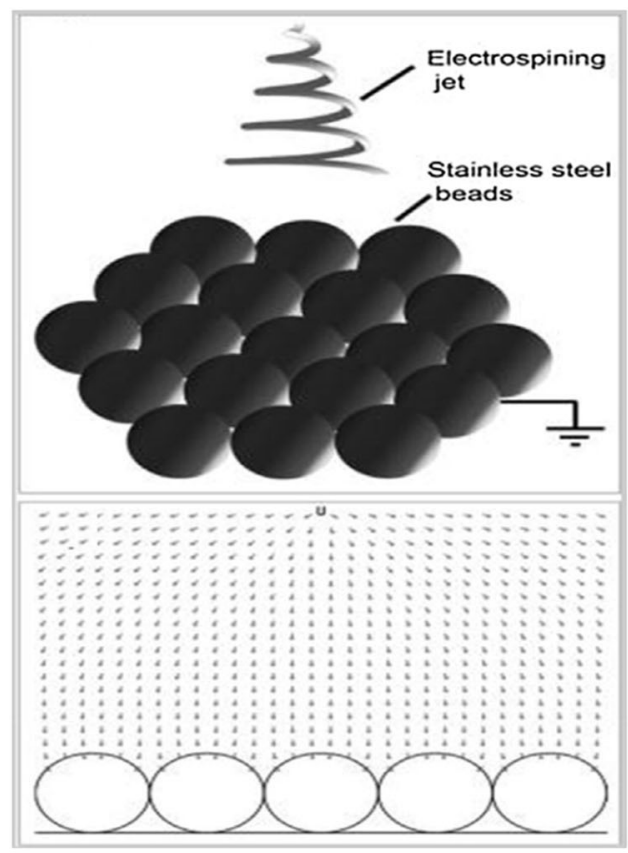

(a)
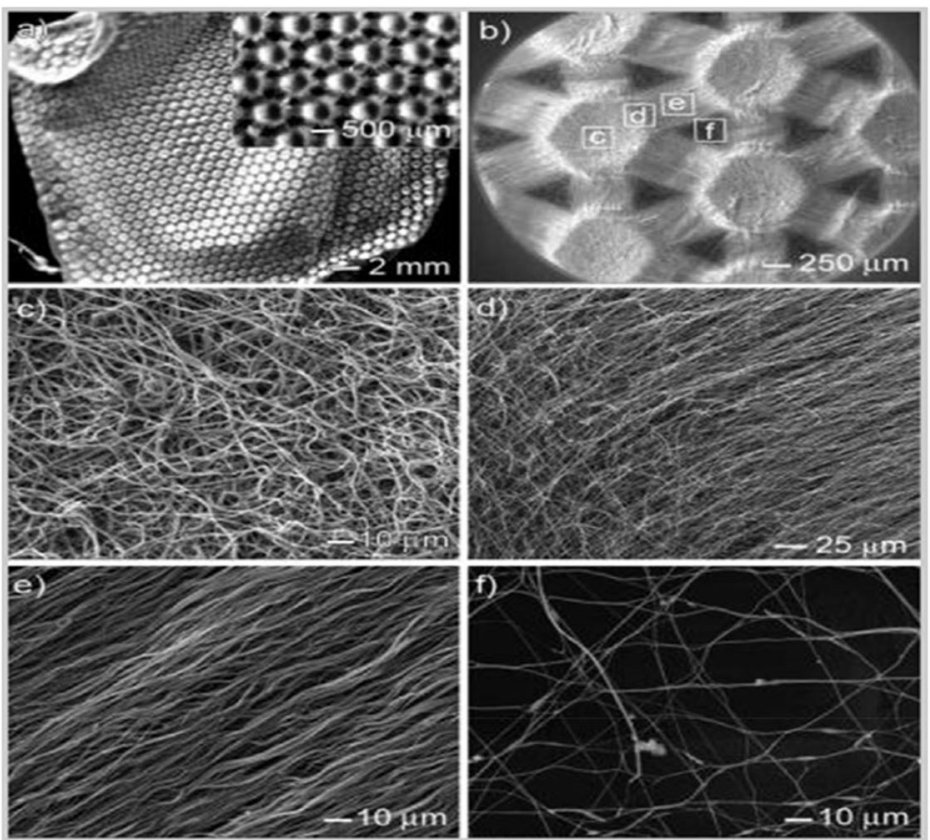

(b)

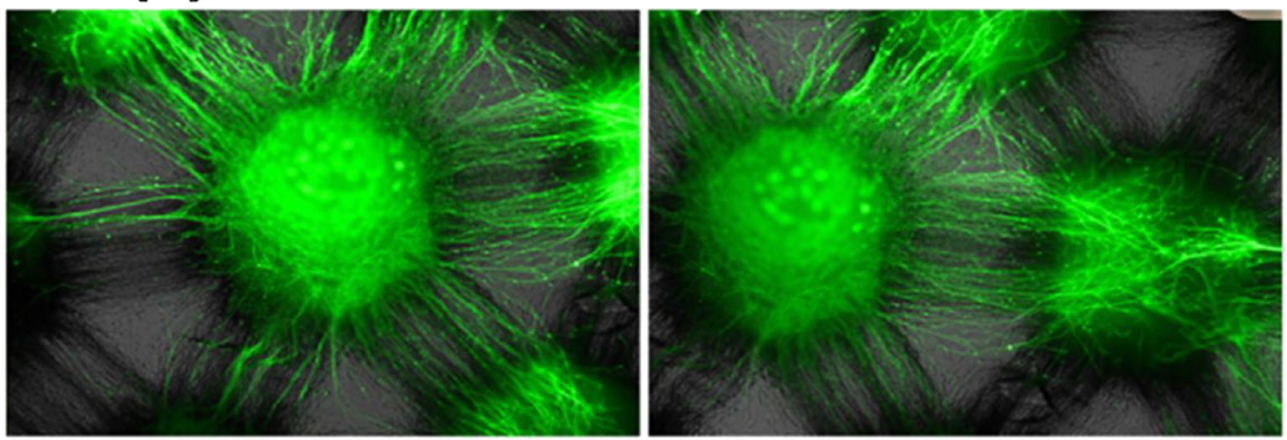

(c)

Fig. 18 a Schematic representation of nanofiber membrane preparation, $\mathbf{b}$ optical micrographs and SEM images of nanofibers from different regions of microwell $\mathbf{c}$ fluorescence image of DRG neurites extended from one well to adjacent well after 6 days of culture [123]

excellent physical, mechanical strength, chemical reactivity and coupled with advanced technology like medical, catalytic, environmental, biosensory, and energy. In most of the cases the synthetic approach employed is top-down approach in the materials synthesis. The cellulose after undergoing electrospinning and obtaining the spun pattern of derivatives exhibits immobilization of biological active molecules or drug and vitamins such as alkannin, amoxicillin, curcumin, ibuprofen, indomethacin, naproxen, shikonin, sulindac, vitamin $\mathrm{A}$, and vitamin $\mathrm{E}$ and these can improve the cell adhesion, proliferation and cell differentiation in the biological applications that too in the drug delivery and tissue engineering. In the tissue engineering, embedded gentamicin sulfate (impart antibacterial activity) and halloysite clay (increases mechanical properties) into cellulose ether-PVA nanofiber mats to deliver therapeutics to the skin tissue and scaffold composite heals the wound of in-vitro and in vivo. Similarly, polyaniline nanorods are preferred to transfer electro spun carboxymethyl cellulose and these are cylindrical and 3D surface materials which provides excellent electroactive surface which envisages electron transfer and mass transportation. Amino based cellulose synthesized by 6-deoxy-6-trisaminoethyl-amino (TEAE) cellulose and polyvinyl alcohol (PVA) blended solutions in aqueous media, and this can be used to stop the growth of $\mathrm{S}$. aureus and this nanomaterial used to cure pneumonia which is caused by Gram-negative K. pneumoniae bacteria. Sodium doped cellulose with tungsten precursor on calcinations exhibits excellent gas (hydrogen disulfide) sensor applications. Starch is obtained from the higher plants used as a storage material and used in the food and nonfood applications. Starch consisting of complex polysaccharides $\alpha$ D-glucopyranosyl units such as amylose and amylopectin 
Fig. 19 Antibacterial activity (A), in-vitro cell migration (B), and in-vivo wound healing experiments of the control and the scaffold [124]
A
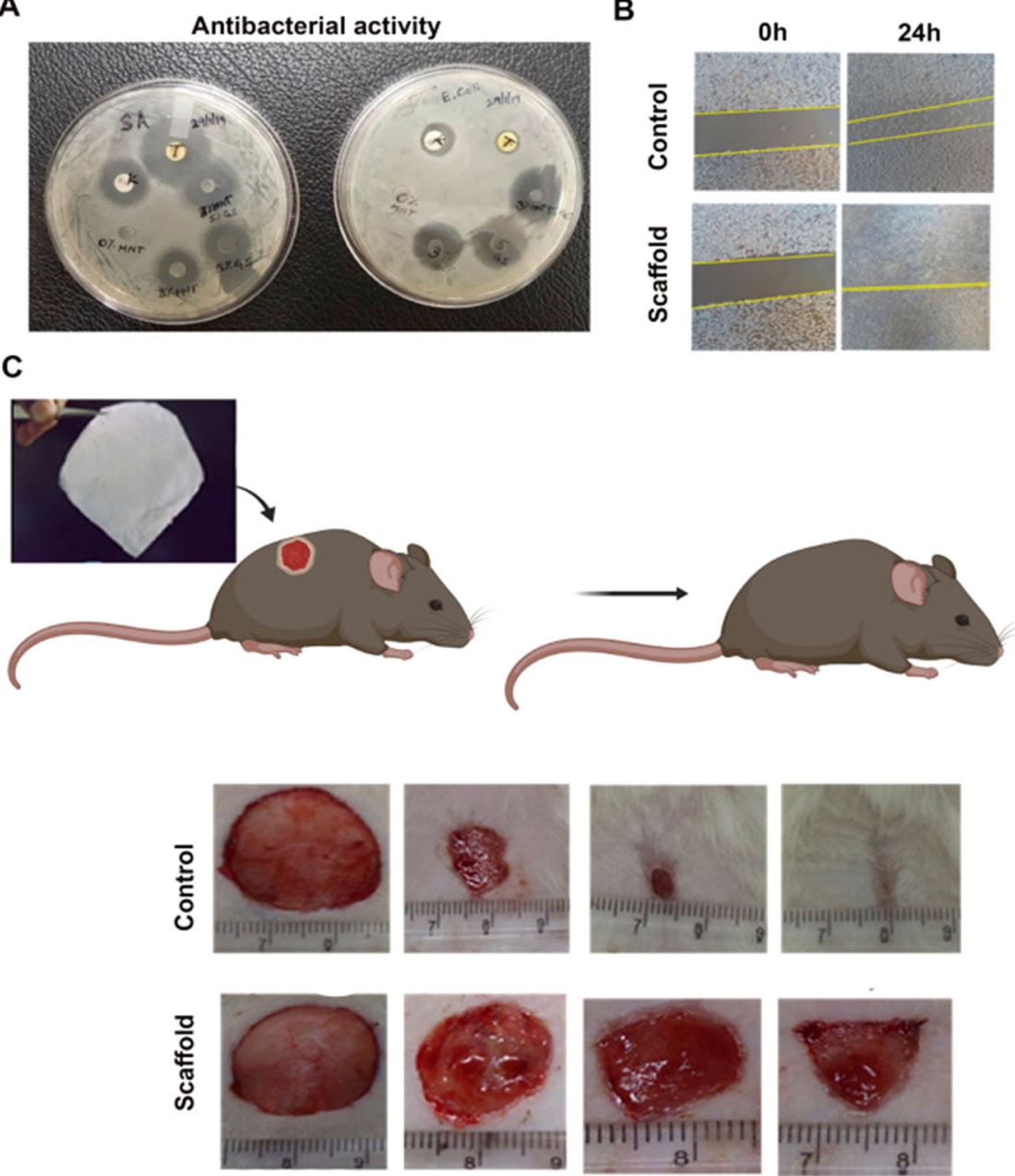

found in wheat, maize, rice, potato, sago, tapioca/cassava, rye, barley, and oats. The starch with nanographene enhances electro spinnability, reduced diameter, improved hydrophilicity, and thermal stability. The starch derived nanotubes coupled with carbon nanotubes as an electrode are used in the rechargeable batteries which give rise outstanding performance. Pectin is obtained by the plants and it is hetero polysaccharide, and major sources are citrus peel, apple pomace, and sugar beet pulp. The pectin is used in the food industries as a thickening, gelling, and stabilizing agent and possesses biomedical applications [122, 123, 124]. Moreover, in Fig. 19, it was seen that the scaffold composite indicated faster in-vitro and in-vivo wound healing. The antimicrobial activity was increased on using the gentamicin.

\section{Summary and conclusions}

The materials which are in nanoscale exhibit various structures like nanospheres, nanoplates, nanorods, nanofibers, nanowires, nanoflowers, nanotubes, nanocages, nanofilms, nanoparticles, nanosheets, nanochains, nanofoam, nanoholes, nanopillar, nanoribbons, quantum wells, quantum dots etc. Amongst, nanofibers/nanorods exhibit different characteristics. Owing to this, we have focused on recent advancements in nanofibers/ nanorods. In this connection, this article provides the brief knowledge on the origin along with synthesis of nanofibers/ nanorods by electrospinning and hydrothermal techniques. Further, various materials showed the nanofiber/nanorod like morphology along with their synthesis techniques, crystal structure and applications are tabulated. Finally, the device applications of nanofibers/nanorods such as nanogenerator melt spun filament and the role of nanofibers in the treatment of tumors are also discussed.

Acknowledgements The authors express thankfulness to Dr. P. Sreeramulu, Assistant Professor (English), GITAM, Bangalore for providing English language editing services to this manuscript.

\section{Compliance with ethical standards}

Conflict of interest The authors declare no competing interests.

Publisher's note Springer Nature remains neutral with regard to jurisdictional claims in published maps and institutional affiliations. 
Open Access This article is licensed under a Creative Commons Attribution 4.0 International License, which permits use, sharing, adaptation, distribution and reproduction in any medium or format, as long as you give appropriate credit to the original author(s) and the source, provide a link to the Creative Commons license, and indicate if changes were made. The images or other third party material in this article are included in the article's Creative Commons license, unless indicated otherwise in a credit line to the material. If material is not included in the article's Creative Commons license and your intended use is not permitted by statutory regulation or exceeds the permitted use, you will need to obtain permission directly from the copyright holder. To view a copy of this license, visit http://creativecommons. org/licenses/by/4.0/.

\section{References}

1. Nasrollahzadeh M, Issaabadi Z, Sajjadi M, Sajadi SM, Atarod M. Types of nanostructures, Interface Sci Technol. 2019;28:29-80. https://doi.org/10.1016/B978-0-12-813586-0.00002-X

2. Raghuram N, Subba Rao T, Naidu KCB. Electrical and impedance spectroscopy properties of hydrothermally synthesized $\mathrm{Ba}_{0.2} \mathrm{Sr}_{0.8}$ ${ }_{\mathrm{y}} \mathrm{LayFe}_{12} \mathrm{O}_{19} \quad(\mathrm{y}=0.2-0.8)$ nanorods. Ceram Int. 2020;46: 5894-906. https://doi.org/10.1016/j.ceramint.2019.11.042

3. Sanchez-Botero L, Herrera AP, Hinestroza JP. Oriented growth of $\alpha-\mathrm{MnO}_{2}$ nanorods using natural extracts from grape stems and apple peels. Nanomaterials. 2017;7:117. https://doi.org/10.3390/ nano7050117

4. Bhardwaj N, Kundu SC. Electrospinning: a fascinating fiber fabrication technique, Biotechnol Adv. 2010;28:325-47. https:// doi.org/10.1016/j.biotechadv.2010.01.004.

5. Lu Bai, Zhaodong Yan, Lu Jia, Zhicheng Liu, Yaqing Liu. Morphology evolution of nanorods decorated on electrospun nanofibers and their applications in SERS and catalysis, Mater Des. 2017;135:9-15. https://doi.org/10.1016/j.matdes.2017.09.010.

6. Yang J, Yuan W, Zhou X, Zhang Y, Zheng Y, Yan Q, et al. Nano-confined $\mathrm{CoSe}_{2} / \mathrm{Mo}_{2} \mathrm{C}$ nanoparticles encapsulated into porous carbon nanofibers for superior lithium and sodium storage. Mater Today Energy. 2018;10:317-24. https://doi.org/10. 1016/j.mtener.2018.10.002

7. Sunaina S, Sreekanth M, Ghosh S, Mehta SK, Ganguli AK, Jha $\mathrm{M}$. Investigation of the growth mechanism of the formation of $\mathrm{ZnO}$ nanorods by thermal decomposition of zinc acetate and their field emission properties. CrystEng Comm. 2017;19:2264-70. https://doi.org/10.1039/C7CE00073A

8. Kumar NS, Suvarna RP, Naidu KCB, Kumar GR, Ramesh S. Structural and functional properties of sol-gel synthesized and microwave heated $\mathrm{Pb}_{0.8} \mathrm{Co}_{0.2-\mathrm{z}} \mathrm{La}_{\mathrm{z}} \mathrm{TiO}_{3}(\mathrm{z}=0.05-0.2)$ nanoparticles. Ceram Int. 2018;44:19408-1942. https://doi.org/10. 1016/j.ceramint.2018.07.176

9. Kumar NS, Suvarna RP, Naidu KCB. Sol-gel synthesized and microwave heated $\mathrm{Pb}_{0.8-\mathrm{y}} \mathrm{LayCo}_{0.2} \mathrm{TiO}_{3}$ (y $=0.2-0.8$ ) nanoparticles: structural, morphological and dielectric properties. Ceram Int. 2018;44:18189-99. https://doi.org/10.1016/j.cera mint.2018.07.027

10. Naresh U, Kumar RJ, Naidu KCB. Optical, magnetic and ferroelectric properties of $\mathrm{Ba}_{0.2} \mathrm{Cu}_{0.8-\mathrm{x}} \mathrm{La}_{\mathrm{x}} \mathrm{Fe}_{2} \mathrm{O}_{4} \quad(\mathrm{x}=0.2-0.6)$ nanoparticles. Ceram Int. 2019;45:7515-23. https://doi.org/10. 1016/j.ceramint.2019.01.044

11. Naresh U, Kumar RJ, Naidu KCB. Hydrothermal synthesis of barium copper ferrite nanoparticles: nanofiber formation, optical, and magnetic properties. Mater Chem Phys. 2019;236:121807. https://doi.org/10.1016/j.matchemphys.2019.121807

12. Reddy BVS, Srinivas K, Kumar NS, Naidu KCB, Ramesh S. Nanorods like microstructure, photocatalytic activity and ac- electrical properties of $(1-\mathrm{x})\left(\mathrm{Al}_{0.2} \mathrm{La}_{0.8} \mathrm{TiO}_{3}\right)+(\mathrm{x})\left(\mathrm{BaTiO}_{3}\right)(\mathrm{x}$ $=0.2,0.4,0.6 \& 0.8)$ nanocomposites. Chem Phys Lett. 2020;752:137552. https://doi.org/10.1016/j.cplett.2020.137552

13. Reddy BVS, Srinivas K, Kumar NS, Naidu KCB. Phase transformation, nanorods like morphology, wide band gap and dielectric properties of 1-x $\left(\mathrm{Al}_{0.2} \mathrm{La}_{0.8} \mathrm{TiO}_{3}\right)+\mathrm{x}\left(\mathrm{BaTiO}_{3}\right)(\mathrm{x}=$ 0.2-0.8) nanocomposites. $J$ Mater Sci: Mater Electron. 2020;31:9293-305. https://doi.org/10.1007/s10854-020-03469-6

14. Prakash M, Jeevan Kumar R, Naidu KCB. Optical and functional properties of hydrothermally synthesized tetragonal $\mathrm{Ba} 0.4 \mathrm{Cu} 0.6$ $-\mathrm{xLaxTiO3}(\mathrm{x}=0.2-0.6)$ nanoparticles. Mater Res Express. 2020;7:015037. https://doi.org/10.1088/2053-1591/ab6494

15. Yu L, Li C, Ma S, Li Y, Qi L, Yin M, et al. Optoelectronic gas sensor sensitized by hierarchically structured $\mathrm{ZnO}$ nanorods/Ag nanofibers via on-chip fabrication. Mater Lett. 2019;242:71-4. https://doi.org/10.1016/j.matlet.2019.01.106

16. da Silva DL, da A, Viegas C, Acuña JJJ, Pasa AA. Nanofiber-tonanorod transformation during annealing of electrochemically deposited vanadium oxide nanofibers. Mater Lett. 2012;68:303-6. https://doi.org/10.1016/j.matlet.2011.10.078

17. Liu Z, Tay SW. Direct growth $\mathrm{Fe}_{2} \mathrm{O}_{3}$ nanorods on carbon fibers as anode materials for lithium ion batteries. Mater Lett. 2012;72:74-7. https://doi.org/10.1016/j.matlet.2011.12.083

18. Sun K, Lu Q, Ma C, Wei M. Pt modified ultrafine $\mathrm{WO}_{3}$ nanofibers: a combined first-principles and experimental study. Mater Lett. 2019;236:267-70. https://doi.org/10.1016/j.matlet. 2018.10.117

19. Gu W, Zhang W, Zhu L, Zou W, Liu H, Fu Z, et al. Synthesis of $\mathrm{Au} @ \mathrm{Bi}_{6} \mathrm{Fe}_{2} \mathrm{Ti}_{3} \mathrm{O}_{18}$ nanofibers and the corona-poling enhanced visible-light-driven photocatalysis. Mater Lett. 2019;241:115-8. https://doi.org/10.1016/j.matlet.2019.01.059

20. Zhang H, Ye J, Qin X. Facile fabrication and transistor properties of mixed crystalline $\mathrm{TiO}_{2}$ nanofibers FET devices. Mater Lett. 2019;246:99-102. https://doi.org/10.1016/j.matlet.2019.03.052

21. Motlak M, Hamza AM, Hammed MG, Barakat NAM. Cd-doped $\mathrm{TiO}_{2}$ nanofibers as effective working electrode for the dye sensitized solar cells. Mater Lett. 2019;246:206-9. https://doi.org/ 10.1016/j.matlet.2019.03.067

22. Chaoqun Ma MW. $\mathrm{BiVO}_{4}$-nanorod-decorated rutile/anatase $\mathrm{TiO}_{2}$ nanofibers with enhanced photoelectrochemical performance. Mater Lett. 2020;259:126849. https://doi.org/10.1016/j.matlet. 2019.126849

23. Zhang R, Abdulla M, Jamal R, Ge Y, Zhang W, Yu Z, et al. The pendent thiol group grafed poly(3,4-proplenedioxythiophene) hollow nanofiber for electrochemical sensing. Mater Lett. 2020;263:127206. https://doi.org/10.1016/j.matlet.2019.127206

24. Ramachandran K, Zahoor A, Kumar TR, Nahm KS, Balasubramani A, Gnana Kumar G. $\mathrm{MnO}_{2}$ nanorods grown NGNF nanocomposites for the application of highly sensitive and selective electrochemical detection of hydrogen Peroxide. J Ind Eng Chem. 2017;46:19-27. https://doi.org/10.1016/j.jiec.2016.09.012

25. Han Y, Kim S, Yu S, Myung NV, Kim H. Electrospun hydrogen manganese oxide nanofibers as effective adsorbents for $\mathrm{Li}^{+}$ recovery from seawater. J Ind Eng Chem. 2020;81:115-23. https://doi.org/10.1016/j.jiec.2019.08.061

26. Shah AP, Jain S, Mokale VJ, Shimpi NG. High performance visible light photocatalysis of electrospun PAN/ZnO hybrid nanofibers. J Ind Eng Chem. 2019;77:154-63. https://doi.org/10. 1016/j.jiec.2019.04.030

27. Kim J, Park H, Jeong S-H. A kirigami concept for transparent and stretchable nanofiber networks-based conductors and UV photodetectors. J Ind Eng Chem. 2020;82:144-52. https://doi. org/10.1016/j.jiec.2019.10.006

28. Phan D-N, Rebia RA, Saito Y, Kharaghani D, Khatri M, Tanaka $\mathrm{T}$, et al. Zinc oxide nanoparticles attached to polyacrylonitrile nanofibers with hinokitiol as gluing agent for synergistic 
antibacterial activities and effective dye removal. J Ind Eng Chem. 2020;85:258-68. https://doi.org/10.1016/j.jiec.2020.02.008

29. Stojanovska E, Ozturk ND, Polat Y, Akbulut H, Kilic A. Solution blown polymer/biowaste derived carbon particles nanofibers: an optimization study and energy storage applications. J Energy Storage. 2019;26:100962. https://doi.org/10.1016/j.est. 2019.100962

30. Dinesh VP, Sriram kumar R, Sukhananazerin A, Mary Sneha J, Manoj Kumar P, Biji P. Novel stainless steel based, eco-friendly dye-sensitized solar cells using electrospun porous $\mathrm{ZnO}$ nanofibers. Nano-Struct Nano-Objects. 2019;19:100311. https://doi. org/10.1016/j.nanoso.2019.100311

31. Shiva Reddy BV, Srinivas K, Kumar NS, Naidu KCB, Ramesh $\mathrm{S}$. Nanorods like microstructure, photocatalytic activity and acelectrical properties of (1-x) $\left(\mathrm{Al}_{0.2} \mathrm{La}_{0.8} \mathrm{TiO}_{3}\right)+(\mathrm{x})\left(\mathrm{BaTiO}_{3}\right)(\mathrm{x}$ $=0.2,0.4,0.6 \& 0.8)$ nanocomposites. Chem Phys Lett. 2020. https://doi.org/10.1016/j.cplett.2020.137552

32. Cao Y, Dong Y-J, Feng H-L, Chen H-Y, Kuang D-B. Electrospun $\mathrm{TiO}_{2}$ nanofiber based hierarchical photoanode for efficient dye-sensitized solar cells. Electrochim Acta. 2016;189:259-64. https://doi.org/10.1016/j.electacta.2015.12.073

33. Xue G, Zhong J, Cheng Y, Wang B. Facile fabrication of crosslinked carbon nanofiber via directly carbonizing electrospun polyacrylonitrile nanofiber as high performance scaffold for supercapacitors. Electrochim Acta. 2016;215:29-35. https://doi. org/10.1016/j.electacta.2016.08.063

34. Cheng Z, Hu Y, Wu K, Xing Y, Pan P, Jiang L, et al. Si/TiO $/$ $\mathrm{Ti}_{2} \mathrm{O}_{3}$ composite carbon nanofiber by one-step heat treatment with highly enhanced ion/electron diffusion rates for next-generation lithium-ion batteries. Electrochim Acta. 2020;337:135789. https:// doi.org/10.1016/j.electacta.2020.135789

35. She L, Zhang F, Jia C, Kang L, Li Q, He X, et al. Electrospun $\mathrm{Nb} 2 \mathrm{O} 5$ nanorods/microporous multichannel carbon nanofiber film anode for $\mathrm{Na}^{+}$ion capacitors with good performance. $\mathrm{J}$ Colloid Interface Sci. 2020;573:1-10. https://doi.org/10.1016/j. jcis.2020.03.122

36. Wang W, Dong W, Tian G, Sun L, Wang Q, Hui A, et al. Highly efficient self-template synthesis of porous silica nanorods from natural palygorskite. Powder Technol. 2019;354:1-10. https:// doi.org/10.1016/j.powtec.2019.05.075

37. Park Y, Oh M, Park JS, Baek S-H, Kim M, Kim S, et al. Electrochemically deposited $\mathrm{Fe}_{2} \mathrm{O}_{3}$ nanorods on carbon nanofibers for free-standing anodes of lithium-ion batteries. Carbon. 2015;94:9-17. https://doi.org/10.1016/j.carbon.2015. 06.031

38. Bui HT, Kim DY, Kim YY, Le NH, Kim DW, Suk J, et al. Macroporous carbon nanofiber decorated with platinum nanorods as free-standing cathodes for high-performance $\mathrm{Li}-\mathrm{O}_{2}$ batteries. Carbon. 2019;154:448-56. https://doi.org/10.1016/j.ca rbon.2019.08.025

39. Shen Y, Qin Z, Hu S, Yang L, Xu X, Ding L, et al. In-situ hybridization of graphene sheets onto polyaniline nanofiber arrays grown on the surface of carbon cloth under high electric voltage field for higheperformance flexible supercapacitor. Carbon. 2020;158:711-8. https://doi.org/10.1016/j.carbon.2019.11.045

40. Wen S, Zhao J, Zhao Y, Xu T, Xu J. Reduced graphene oxide (RGO) decorated $\mathrm{Sb}_{2} \mathrm{~S}_{3}$ nanorods as anode material for sodiumion batteries. Chem Phys Lett. 2019;716:171-6. https://doi.org/ 10.1016/j.cplett.2018.12.031

41. Zeng Y, Yang P, Yang L, Hao Y, Shi T, Wang J, et al. In situ growth of $\mathrm{CsPbI}_{3}$ on carbon nanofibers via electrospinning. Chem Phys Lett. 2019;723:11-5. https://doi.org/10.1016/j.cplett. 2019.02.052

42. Wu M-S, Ou Y-H, Lin Y-P. Electrodeposition of iron oxide nanorods on carbon nanofiber scaffolds as an anode material for lithium-ion batteries. Electrochim Acta. 2010;55:3240-4. https:// doi.org/10.1016/j.electacta.2009.12.100

43. Peng H, Ma G, Sun K, Mu J, Luo M, Lei Z. High-performance aqueous asymmetric supercapacitor based on carbon nanofibers network and tungsten trioxide nanorod bundles electrodes. Electrochim Acta. 2014;147:54-61. https://doi.org/10.1016/j. electacta.2014.09.100

44. Zhu J, Zhang G, Gu S, $\mathrm{Lu} \mathrm{B}$. $\mathrm{SnO}_{2}$ nanorods on $\mathrm{ZnO}$ nanofibers: a new class of hierarchical nanostructures enabled by electrospinning as anode material for high-performance lithium-ion batteries. Electrochim Acta. 2014;150:308-13. https://doi.org/10. 1016/j.electacta.2014.10.149

45. Bhagwan J, Sahoo A, Yadav KL, Sharma Y. Porous, one dimensional and high aspect ratio $\mathrm{Mn}_{3} \mathrm{O}_{4}$ nanofibers: fabrication and optimization for enhanced supercapacitive properties. Electrochim Acta. 2015;174:992-1001. https://doi.org/10.1016/j. electacta.2015.06.073

46. Song HJ, Kim J-C, Choi M, Choi C, Dar MA, Lee CW, et al. $\mathrm{Li}_{2} \mathrm{MnSiO}_{4}$ nanorods-embedded carbon nanofibers for lithiumion battery electrodes. Electrochim Acta. 2015;180:756-62. https://doi.org/10.1016/j.electacta.2015.08.161

47. Zhang M, Wang SS, Li T, Chen JD, Zhu H, Du ML. Nitrogen and gold nanoparticles co-doped carbon nanofiber hierarchical structures for efficient hydrogen evolution reactions. Electrochim Acta. 2016;208:1-9. https://doi.org/10.1016/j.electacta.2016.04.104

48. Chang W-M, Wang C-C, Chen C-Y. Plasma-induced polyaniline grafted on carbon nanotube-embedded carbon nanofibers for highperformance supercapacitors. Electrochim Acta. 2016;212:130-40. https://doi.org/10.1016/j.electacta.2016.06.159

49. Yang Y, Zeng D, Gu L, Liu B, Guo F, Ren Y, et al. Supportinduced morphology and content tailored $\mathrm{NiCo}_{2} \mathrm{O}_{4}$ nanostructures on temperature-dependent carbon nanofibers with enhanced pseudocapacitive performance. Electrochim Acta. 2018;286:1-13. https://doi.org/10.1016/j.electacta.2018.08.026

50. Li J, Xiao D, Ren Y, Liu H, Chen Z, Xiao J. Bridging of adjacent graphene/polyaniline layers with polyaniline nanofibers for supercapacitor electrode materials. Electrochim Acta. 2019;300: 193-201. https://doi.org/10.1016/j.electacta.2019.01.089

51. Yang Y, Deng B-W, Liu X, Li Y, Yin B, Yang M-B. Rational design of $\mathrm{MnO}_{2}$-nanosheets-decroated hierarchical porous carbon nanofiber frameworks as high-performance supercapacitor electrode materials. Electrochim Acta. 2019;324:134891. https:// doi.org/10.1016/j.electacta.2019.134891

52. Jayasingha L, Jayathilaka C, Kumara R, Ohara K, Kaumal M, Gunewardene $\mathrm{S}$, et al. Nanoporous $\mathrm{Cu}_{2} \mathrm{O}$ nanotube/nanorod array electrodes for non-enzymatic glucose sensing with high sensitivity and very low detection limit. Electrochim Acta. 2020;329:135177. https://doi.org/10.1016/j.electacta.2019.135177

53. Hu C, Zhang X, Liu B, Chen S, Liu X, Liu Y, et al. Orderly and highly dense polyaniline nanorod arrays fenced on carbon nanofibers for all-solid-state flexible electrochemical energy storage. Electrochim Acta. 2020;338:135846. https://doi.org/10. 1016/j.electacta.2020.135846

54. Wang H, Cai W, Wang S, Li B, Yang Y, Li Y, et al. Fabrication of helical $\mathrm{SiO}_{2} @$ FeeN doped C nanofibers and their applications as stable lithium ion battery anodes and superior oxygen reduction reaction catalysts. Electrochim Acta. 2020;342:136107. https://doi. org/10.1016/j.electacta.2020.136107

55. Cao M, Cheng W, Ni X, Hu Y, Han G. Lignin-based multichannels carbon nanofibers@ $\mathrm{SnO}_{2}$ nanocomposites for highperformance supercapacitors. Electrochim Acta. 2020;345: 136172. https://doi.org/10.1016/j.electacta.2020.136172

56. Dulgerbaki C, Maslakci NN, Komur AI, Oksuz AU. Electrochromic strategy for tungsten oxide/polypyrrole hybrid nanofiber Materials. Eur Polym J. 2018;107:173-80. https://doi.org/10. 1016/j.eurpolymj.2018.07.050 
57. Bairagi S, Ali SW. A unique piezoelectric nanogenerator composed of melt-spun PVDF/KNN nanorod-based nanocomposite fibre. Eur Polym J. 2019;116:554-61. https://doi.org/10.1016/j. eurpolymj.2019.04.043

58. Guan W, Li S, Tang L. Fabrication polymer nanofiber networks with regulated microstructures via RAFT polymerization of supramolecular gels in different solvents. Eur Polym J. 2019; 120:109210. https://doi.org/10.1016/j.eurpolymj.2019.08.037

59. Nair AS, Jose R, Shengyuan Y, Ramakrishna S. A simple recipe for an efficient $\mathrm{TiO}_{2}$ nanofiber-based dye-sensitized solar cell. J Colloid Interface Sci. 2011;353:39-45. https://doi.org/10.1016/j. jcis.2010.09.042

60. Ocal SK, Patarroyo J, Kiremitler NB, Pekdemir S, Puntes VF, Onses MS. Plasmonic assemblies of gold nanorods on nanoscale patterns of poly (ethylene glycol): application in surfaceenhanced Raman spectroscopy. J Colloid Interface Sci. 2018;532:449-55. https://doi.org/10.1016/j.jcis.2018.07.124

61. Sun J, Liu J, Chen H, Han X, Wu Y, He J, et al. Strongly coupled $\mathrm{Mo}_{2} \mathrm{C}$ and $\mathrm{Ni}$ nanoparticles with in-situ formed interfaces encapsulated by porous carbon nanofibers for efficient hydrogen evolution reaction under alkaline conditions. J Colloid Interface Sci. 2020;558:100-5. https://doi.org/10.1016/j.jcis.2019.09.102

62. Ranjith KS, Satilmis B, Huh YS, Han Y-K, Uyar T. Highly selective surface adsorption-induced efficient photodegradation of cationic dyes on hierarchical $\mathrm{ZnO}$ nanorod-decorated hydrolyzed PIM-1 nanofibrous webs. J Colloid Interface Sci. 2020;562:29-41. https://doi.org/10.1016/j.jcis.2019.11.096

63. Wang H-L, Ma X-D, Qian X-F, Yin J, Z. Zhu K. Selective synthesis of CdWO4 short nanorods and nanofibers and their self-assembly. J Solid State Chem. 2004;177:4588-96. https:// doi.org/10.1016/j.jssc.2004.09.012

64. Sun D, Lang J, Yann X, Hu L, Xue Q. Fabrication of TiN nanorods by electrospinning and their electrochemical properties, J Solid State Chem. 2011;184:1333-8. https://doi.org/10.1016/j. jssc. 2011.03.053

65. Rasaki SA, Zhao C, Wang R, Wang J, Jiang H, Yang M. Facile synthesis approach for preparation of robust and recyclable $\mathrm{Ag} /$ $\mathrm{ZnO}$ nanorods with high catalytic activity for 4-nitrophenol reduction. Mater Res Bull. 2019;119:110536. https://doi.org/10. 1016/j.materresbull.2019.110536

66. Zhao X, Wang D, Liu S'an, Li Z, Meng J, Rand Y, et al. $\mathrm{Bi}_{2} \mathrm{~S}_{3}$ nanoparticles densely grown on electrospun-carbon-nanofibers as low cost counter electrode for liquid-state solar cells. Mater Res Bull. 2020;125:110800. https://doi.org/10.1016/j.ma terresbull.2020.110800

67. Chen C, Bai Z, Cao Y, Dong M, Jiang K, Zhou Y, et al. Enhanced piezoelectric performance of $\mathrm{BiCl}_{3} / \mathrm{PVDF}$ nanofibersbased nanogenerators. Compos Sci Technol. 2020;192:108100. https://doi.org/10.1016/j.compscitech.2020.108100

68. Moosavifard SE, Shamsi J, Fani S, Kadkhodazade S. Facile synthesis of hierarchical $\mathrm{CuO}$ nanorod arrays on carbon nanofibers for high-performance supercapacitors. Ceram Int. 2014;40:15973-15979. https://doi.org/10.1016/j.ceramint. 2014.07.126

69. Rajaei E, Ravandi SAH, Valipouri A. Electrochemical and photovoltaic properties of dye-sensitized solar cells based on Agdoped $\mathrm{TiO}_{2}$ nanorods. Optik. 2018;158:514-21. https://doi.org/ 10.1016/j.ijleo.2017.12.168

70. Na K-H, Kim W-T, Park D-C, Shin H-G, Lee S-H, Park J, et al. Fabrication and characterization of the magnetic ferrite nanofibers by electrospinning process. Thin Solid Films. 2018;660:358-64. https://doi.org/10.1016/j.tsf.2018.06.018

71. Sarıca N, Alev O, Arslan LÇ, ZiyaÖztürk Z. Characterization and gas sensing performances of noble metals decorated $\mathrm{CuO}$ nanorods. Thin Solid Films. 2019;685:321-8. https://doi.org/10. 1016/j.tsf.2019.06.046
72. Qiu J, Liu F, Yue C, Ling C, Li A. A recyclable nanosheet of $\mathrm{Mo} / \mathrm{N}$-doped $\mathrm{TiO}_{2}$ nanorods decorated on carbon nanofibers for organic pollutants degradation under simulated sunlight irradiation. Chemosphere. 2019;215:280-93. https://doi.org/10.1016/j. chemosphere.2018.09.182

73. Huang R, Li Y, Song Y, Wang L. Facial preparation of N-doped carbon foam supporting $\mathrm{Co}_{3} \mathrm{O}_{4}$ nanorod arrays as free-standing lithium-ion batteries' anode. J Alloy Compd. 2020;818:152839. https://doi.org/10.1016/j.jallcom.2019.152839

74. Guo S, Zhang P, Feng Y, Wang Z, Li X, Yao J. Rational design of interlaced $\mathrm{Co}_{9} \mathrm{~S}_{8} /$ carbon composites from ZIF-67/cellulose nanofibers for enhanced lithium storage. J Alloy Compd. 2020;818: 152911. https://doi.org/10.1016/j.jallcom.2019.152911

75. Tahmasebi N, Sezari S, Zaman P. Fabrication and characterization of hydrogen-treated tungsten oxide nanofibers for cationic dyes removal from water. Solid State Sci. 2020;100:106073. https://doi.org/10.1016/j.solidstatesciences.2019.106073

76. Suenaga S, Osada M. Systematic dynamic viscoelasticity measurements for chitin nanofibers prepared with various concentrations, disintegration times, acidities, and crystalline structures. Int J Biol Macromol. 2018;115:431-7. https://doi.org/ 10.1016/j.ijbiomac.2018.04.082

77. Bhutiya PL, Misra N, Rasheed MA, Hasan SZ. Nested seaweed cellulose fiber deposited with cuprous oxide nanorods for antimicrobial activity. Int J Biol Macromol. 2018;117:435-44. https://doi.org/10.1016/j.ijbiomac.2018.05.210

78. Farboudi A, Nouri A, Shirinzad S, Sojoudi P, Davaran S, Akrami $\mathrm{M}$, et al. Synthesis of magnetic gold coated poly (e-caprolactonediol) based polyurethane/poly(N-isopropylacrylamide)-grafted-chitosan core-shellnanofibers for controlled release of paclitaxel and 5-FU. Int J Biol Macromol. 2020;150:1130-40. https://doi.org/10.1016/j.ijbiomac.2019.10.120

79. Szala M, Borkowski A. Toxicity assessment of SiC nanofibers and nanorods against bacteria. Ecotoxicol Environ Saf. 2014;100:287-93. https://doi.org/10.1016/j.ecoenv.2013.10.030

80. Li J, Chen X, Xu D, Pan K. Immobilization of horseradish peroxidase on electrospun magnetic nanofibers for phenol removal. Ecotoxicol Environ Saf. 2019;170:716-21. https://doi. org/10.1016/j.ecoenv.2018.12.043

81. Mehrani Z, Ebrahimzadeh H, Moradi E, Yamini Y. Using three-dimensional poly (vinyl alcohol)/sodium hexametaphosphate nanofiber as a non-toxic and efficient nanosorbent for extraction and recovery of Lanthanide ions from aqueous solutions. J Mol Liq. 2020;307:112925. https://doi.org/10. 1016/j.molliq.2020.112925

82. Meng D, Liu D, Wang G, Shen Y, San X, Si J, et al. In-situ growth of ordered $\mathrm{Pd}$-doped $\mathrm{ZnO}$ nanorod arrays on ceramic tube with enhanced trimethylamine sensing performance. Appl Surf Sci. 2019;463:348-56. https://doi.org/10.1016/j.apsusc. 2018.08.228

83. Kihara R, Imada S, Kawai T, Asahi T. Fabrication of nanorods colloids of copper hexadecafluorophthalocyanine by nanosecond-pulse laser fragmentation in organic solvents. Appl Surf Sci. 2019;478:532-8. https://doi.org/10.1016/j.apsusc.2019. 01.221

84. Kim K, Kim S, Lee HN, Park YM, Bae Y-S, Kim H-J. Electrochemically derived $\mathrm{CuO}$ nanorod from copper-based metalorganic framework for non-enzymatic detection of glucose. Appl Surf Sci. 2019;479:720-6. https://doi.org/10.1016/j.apsusc.2019. 02.130

85. Hosseini ZS, Bafrani HA, Naseri A, Moshfegh AZ. Highperformance UV-Vis-NIR photodetectors based on plasmonic effect in $\mathrm{Au}$ nanoparticles/ZnO nanofibers. Appl Surf Sci. 2019;483:1110-7. https://doi.org/10.1016/j.apsusc.2019.03.284

86. Jiang T, Du B, Zhang H, Yu D, Sun L, Zhao G, et al. Highperformance photoluminescence-based oxygen sensing with $\mathrm{Pr}$ 
modified ZnO nanofibers. Appl Surf Sci. 2019;483:922-8. https://doi.org/10.1016/j.apsusc.2019.04.053

87. Shen Y, Zhong X, Zhang J, Li T, Zhao S, Cui B, et al. In-situ growth of mesoporous $\mathrm{In}_{2} \mathrm{O}_{3}$ nanorod arrays on a porous ceramic substrate for ppb-level $\mathrm{NO}_{2}$ detection at room temperature. Appl Surf Sci. 2019;498:143873. https://doi.org/10.1016/j.apsusc. 2019.143873

88. Han C, Shi J, Yang S, Wang Y, Xie K, Song X, et al. Phase transition behavior in $\mathrm{Fe}_{2} \mathrm{O}_{3}$ nanofibers. Appl Surf Sci. 2020;507:145179. https://doi.org/10.1016/j.apsusc.2019.145179

89. Kebabsa L, Kim J, Lee D, Lee B. Highly porous cobalt oxidedecorated carbon nanofibers fabricated from starch as freestanding electrodes for supercapacitors. Appl Surf Sci. 2020;511:145313. https://doi.org/10.1016/j.apsusc.2020.145313

90. Zhai H, Jiang H, Qian Y, Cai X, Liu H, Qiu Y, et al. $\mathrm{Sb}_{2} \mathrm{~S}_{3}$ nanocrystals embedded in multichannel $\mathrm{N}$-doped carbon nanofiber for ultralong cycle life sodium-ion batteries. Mater Chem Phys. 2020;240:122139. https://doi.org/10.1016/j.matchemphys. 2019.122139

91. Wang C, Li X, Tong C, Cai A, Guo H, Yin H. Preparation, in vitro bioactivity and osteoblast cell response of $\mathrm{Ca}-\mathrm{Ta}_{2} \mathrm{O}_{5}$ nanorods on tantalum. Surf Coat Technol. 2020;391:125701. https://doi.org/10.1016/j.surfcoat.2020.125701

92. Lu F, Wang J, Chang Z, Zeng J. Uniformdeposition of Ag nanoparticles on $\mathrm{ZnO}$ nanorod arrays grown on polyimide/Ag nanofibers by electrospinning, hydrothermal, and photoreduction processes. Mater Des. 2019;181:108069. https://doi.org/10.1016/ j.matdes.2019.108069

93. Lu F, Wang J, Sun X, Chang Z. 3D hierarchical carbon nanofibers $/ \mathrm{TiO}_{2} @ \mathrm{MoS}_{2}$ core-shell heterostructures by electrospinning, hydrothermal and in-situ growth for flexible electrode materials. Mater Des. 2020;189:108503. https://doi.org/10.1016/ j.matdes.2020.108503

94. Nain R, Jassal M, Agrawal AK. Polymeric nanofiber composites with aligned $\mathrm{ZnO}$ nanorods. Compos Sci Technol. 2013;86:9-17. https://doi.org/10.1016/j.compscitech.2013.06.017

95. Ghouri ZK, Barakat NAM, Park M, Kim B-S, Kim HY. Synthesis and characterization of $\mathrm{Co} / \mathrm{SrCO}_{3}$ nanorods-decorated carbon nanofibers as novel electrocatalysts form ethanol oxidation in alkaline medium. Ceram Int. 2015;41:6575-82. https:// doi.org/10.1016/j.ceramint.2015.01.103

96. Kurtan U, Dursun D, Aydın H, Toprak MS, Baykal A, Bozkurt A. Influence of calcination rate on morphologies and magnetic properties of $\mathrm{MnFe}_{2} \mathrm{O}_{4}$ nanofibers. Ceram Int. 2016;42:18189-95. https://doi.org/10.1016/j.ceramint.2016.08.135

97. Selim MS, Mo PJ, Zhang YP, Hao Z, Wen H. Controlledsurfactant-directed solvothermal synthesis of $\gamma$-Al2O3 nanorods through a boehmite precursor route. Ceram Int. 2020;46:9289-96. https://doi.org/10.1016/j.ceramint.2019.12.183

98. Hu X-Y, Liu Q-Y, Jing M-X, Chen F, Ju B-W, Tu F-Y, et al. Controllable preparation of alumina nanorods with improved solid electrolyte electrochemical performance. Ceram Int. 2020;46: 16224-34. https://doi.org/10.1016/j.ceramint.2020.03.178

99. Zhang H, Fu D, Du Z, Fu H, Shao G, Yang W, et al. In situ growth of aligned $\mathrm{CsPbBr}_{3}$ nanorods in polymer fibers with tailored aspect ratios. Ceram Int. 2020;46:18352-7. https://doi. org/10.1016/j.ceramint.2020.04.035

100. Li Y, Cao T, Mei Z, Li X, Sun D. Separating type I heterojunction of $\mathrm{NaBi}\left(\mathrm{MoO}_{4}\right)_{2} / \mathrm{Bi}_{2} \mathrm{MoO}_{6}$ by $\mathrm{TiO}_{2}$ nanofibers for enhanced visible-photocatalysis. Chem Phys. 2020;533:110696. https://doi.org/10.1016/j.chemphys.2020.110696

101. Li S, Huang X, Liu J, Lu L, Peng K, Bhattarai R. PVA/PEI crosslinked electrospun nanofibers with embedded $\mathrm{La}(\mathrm{OH})_{3}$ nanorod for selective adsorption of high flux low concentration phosphorus. J Hazard Mater. 2020;384:121457. https://doi.org/ 10.1016/j.jhazmat.2019.121457
102. Yousef A, Barakat NAM, El-Newehy M, Kim HY. Chemically stable electrospunNiCunanorods@carbon nanofibers for highly efficient dehydrogenation of ammonia borane. Int $\mathrm{J}$ Hydrog Energy. 2012;37:17715-23. https://doi.org/10.1016/j.ijhydene. 2012.09.038

103. Al-Enizi AM, Brooks RM, El-Halwany MM, Yousef A, Nafady A, Hameed RMA. $\mathrm{CoCr}_{7} \mathrm{C}_{3}$-like nanorods embedded on carbon nanofibers as effective electrocatalyst for methanol electrooxidation. Int J Hydrog Energy. 2018;43:9943-9953. https://doi. org/10.1016/j.ijhydene.2018.04.069

104. Chinnappan A, Dongxiao J, Jayathilaka WADM, Baskar C, Qin X, Ramakrishna S. Facile synthesis of electrospunC@NiO/Ni nanofibers as an electrocatalyst for hydrogen evolution reaction. Int J Hydrog Energy. 2018;43:15217-24. https://doi.org/10. 1016/j.ijhydene.2018.06.102

105. Eisa T, Mohamed HO, Choi Y-J, Park S-G, Ali R, Abdelkareem MA, et al. Nickel nanorods over nickel foam as standalone anode for direct alkaline methanol and ethanol fuel cell. Int J Hydrog Energy. 2020;45:5948-59. https://doi.org/10.1016/j.ijhydene. 2019.08.071

106. Lee J-H, Kim J-Y, Kim J-H, Mirzaei A, Kim HW, Kim SS. $\mathrm{Co}_{3} \mathrm{O}_{4}$-loaded $\mathrm{ZnO}$ nanofibers for excellent hydrogen sensing. Int J Hydrog Energy. 2020;45:5948-59. https://doi.org/10.1016/ j.ijhydene.2019.08.226

107. Wang F, Hu K, Liu H, Zhao Q, Wang K, Zhang Y. Low temperature and fast response hydrogen gas sensor with Pd coated $\mathrm{SnO}_{2}$ nanofiber rods. Int J Hydrog Energy. 2020;45:7234-42. https://doi.org/10.1016/j.ijhydene.2019.12.152

108. Patil JV, Mali SS, Patil AP, Patil PS, Hong CK. Highly efficient mixed-halide mixed-cation perovskite solar cells based on rGO$\mathrm{TiO}_{2}$ composite nanofibers. Energy. 2019;189:116396. https:// doi.org/10.1016/j.energy.2019.116396

109. Wu C, Li X, Li W, Li B, Wang Y, Wang Y, et al. $\mathrm{Fe}_{2} \mathrm{O}_{3}$ nanorods/ carbon nanofibers composite: preparation and performance as anode of high rate lithium ion battery. J Power Sources. 2014;251:85-91. https://doi.org/10.1016/j.jpowsour.2013.11.030

110. Li L, Lu Q, Xiao J, Li J, Mi H, Duan R, et al. Synthesis of highly effective $\mathrm{MnO}_{2}$ coated carbon nanofibers composites as low cost counter electrode for efficient dye-sensitized solar cells. J Power Sources. 2017;363:9-15. https://doi.org/10.1016/j.jpowsour. 2017.07.060

111. Cao Y, Lu H, Hong Q, Bai J, Wang J, Li X. Co decorated Ndoped porous carbon nanofibers as a free-standing cathode for $\mathrm{Li}-$ $\mathrm{O}_{2}$ battery: emphasis on seamlessly continuously hierarchical 3D nano-architecture networks. J Power Sources. 2017;368:78-87. https://doi.org/10.1016/j.jpowsour.2017.09.071

112. Gao Q, Zhang X, Duan L, Li X, Lu W. Au nanoparticledecorated $\mathrm{TiO}_{2}$ nanorod array for plasmon enhanced quantum dot sensitized solar cells. Superlattices Microstruct. 2019;129:185-92. https://doi.org/10.1016/j.spmi.2019.03.028

113. A. Tyagia, N. Singha, Y. Sharma, R. K. Gupta, Improved supercapacitive performance in electrospun $\mathrm{TiO}_{2}$ nanofibers through Ta-doping for electrochemical capacitor applications, Catal Today. 2019;325:33-40, https://doi.org/10.1016/j.cattod. 2018.06.026

114. Nirmala R, Navamathavan R, Won JJ, Jeon KS, Yousef A, Kim HY. Synthesis and characterizations of Pt nanorods on electrospun polyamide-6 nanofibers templates. Mater Sci Eng B. 2012;177:826-31. https://doi.org/10.1016/j.mseb.2012.03.047

115. Chu X, Wang J, Bai L, Dong Y, Sun W. The gas sensing properties of $\mathrm{NiGa}_{2} \mathrm{O}_{4}$ nanofibers prepared by electrospinning method. Mater Sci Eng B. 2018;228:45-51. https://doi.org/10. 1016/j.mseb.2017.11.003

116. Ma J, Wang Y, Chen K. Refining single-crystalline epsilon iron oxide nanorods via low-temperature aging. Adv Powder Technol. 2019;30:3021-7. https://doi.org/10.1016/j.apt.2019.09.009 
117. Li Y, Gong J, Deng Y. Hierarchical structured ZnO nanorods on $\mathrm{ZnO}$ nanofibers and their photoresponse to UV and visible lights. Sens Actuators A. 2010;158:176-82. https://doi.org/10.1016/j. sna.2009.12.030

118. Jyothilal H, Shukla G, Walia S, Kundu S, Angappane S. Humidity sensing and breath analyzing applications of $\mathrm{TiO}_{2-}$ slantednanorod arrays. Sens Actuators A. 2020;301:111758. https://doi.org/10.1016/j.sna.2019.111758

119. Wang D, Wan K, Zhang M, Li H, Wang P, Wang X, et al. Constructing hierarchical $\mathrm{SnO}_{2}$ nanofiber/nanosheets for efficient formaldehyde detection. Sens Actuators: B Chem. 2019;283:714-23. https://doi.org/10.1016/j.snb.2018.11.125

120. Bhati VS, Nathani A, Nigam A, Sharma CS, Kumar M. PAN/ (PAN-b-PMMA) derived nanoporous carbon nanofibers loaded on $\mathrm{ZnO}$ nanostructures for hydrogen detection. Sens Actuators: B Chem. 2019;299:126980. https://doi.org/10.1016/j.snb.2019. 126980
121. Feng C, Jiang Z, Wu J, Chen B, Lu G, Huang C. Pt- $\mathrm{Cr}_{2} \mathrm{O}_{3}-\mathrm{WO}_{3}$ composite nanofibers as gas sensors for ultra-high sensitive and selective xylene detection. Sens Actuators: B Chem. 2019;300:127008. https://doi.org/10.1016/j.snb.2019.127008

122. Adhikari SP, Pant HR, Mousa HM, Lee J, Kim HJ, Park CH, et al. Synthesis of high porous electrospun hollow $\mathrm{TiO}_{2}$ nanofibers for bonetissue engineering application. J Ind Eng Chem. 2016;35:75-82. https://doi.org/10.1016/j.jiec.2015.12.004

123. Patel M, Hong HJ, Koh W-G. Micropatternedfibrous scaffolds for biomedical application. J Ind Eng Chem. 2019;80:729-38. https://doi.org/10.1016/j.jiec.2019.02.029

124. Kumar KPA, Nazarzadeh Zare E, Torres-Mendieta R, Wacławek S, Makvandi P, Černík M, et al. Electrospun fibers based on botanical, seaweed, microbial, and animal sourced biomacromolecules and their multidimensional applications. Int $\mathbf{J}$ Biol Macromol. 2021;171:130-49. https://doi.org/10.1016/j.ijbiomac. 2020.12.205 